\title{
Reversal of pentylenetetrazole-altered swimming and neural activity-regulated gene expression in zebrafish larvae by valproic acid and valerian extract
}

\author{
Bianca A. Torres-Hernández ${ }^{1}$ Luis R. Colón ${ }^{2} \cdot$ Coral Rosa-Falero $^{1} \cdot$ Aranza Torrado $^{2}$. \\ Nahira Miscalichi ${ }^{2}$ • José G. Ortíz ${ }^{1}$ • Lorena González-Sepúlveda ${ }^{3}$ - Naydi Pérez-Ríos ${ }^{3}$. \\ Erick Suárez-Pérez $^{3} \cdot$ John N. Bradsher ${ }^{2} \cdot$ Martine Behra $^{2}$
}

Received: 29 May 2015 / Accepted: 15 April 2016/Published online: 11 May 2016

(C) The Author(s) 2016. This article is published with open access at Springerlink.com

\begin{abstract}
Rationale Ethnopharmacology has documented hundreds of psychoactive plants awaiting exploitation for drug discovery. A robust and inexpensive in vivo system allowing systematic screening would be critical to exploiting this knowledge.

Objective The objective of this study was to establish a cheap and accurate screening method which can be used for testing psychoactive efficacy of complex mixtures of unknown composition, like plant crude extracts.

Methods We used automated recording of zebrafish larval swimming behavior during light vs. dark periods which we reproducibly altered with an anxiogenic compound, pentylenetetrazole (PTZ). First, we reversed this PTZ-altered swimming by co-treatment with a well-defined synthetic anxiolytic drug, valproic acid (VPA). Next, we aimed at reversing it by adding crude root extracts of Valeriana officinalis (Val) from which VPA was originally derived. Finally, we assessed how expression of neural activity-regulated genes
\end{abstract}

Electronic supplementary material The online version of this article (doi:10.1007/s00213-016-4304-z) contains supplementary material, which is available to authorized users.

Martine Behra

martine.behra@upr.edu

1 School of Medicine, Department of Pharmacology and Toxicology, Medical Science Campus of the University of Puerto Rico (MCS-UPR), San Juan, PR, USA

2 School of Medicine, Department of Anatomy and Neurobiology, Medical Science Campus of the University of Puerto Rico (MCS-UPR), San Juan, PR, USA

3 Puerto Rico Clinical and Translational Research Consortium (PRCTRC), Medical Science Campus of the University of Puerto Rico (MCS-UPR), San Juan, PR, USA (c-fos, npas4a, and bdnf) known to be upregulated by PTZ treatment was affected in the presence of Val.

Results Both VPA and Val significantly reversed the PTZaltered swimming behaviors. Noticeably, Val at higher doses was affecting swimming independently of the presence of PTZ. A strong regulation of all three neural-activity genes was observed in Val-treated larvae which fully supported the behavioral results.

Conclusions We demonstrated in a combined behavioralmolecular approach the strong psychoactivity of a natural extract of unknown composition made from $V$. officinalis. Our results highlight the efficacy and sensitivity of such an approach, therefore offering a novel in vivo screening system amenable to high-throughput testing of promising ethnobotanical candidates.

Keywords Crude extracts $\cdot$ In vivo high-throughput psychoactivity screening $\cdot$ Psychoactive plants $\cdot$ Zebrafish larva behavior $\cdot$ Valerian $\cdot$ Ethnobotany $\cdot c$-fos $\cdot$ npas $4 a \cdot b d n f$

\section{Introduction}

Extensive ethnopharmaceutical documentation is available on plants with demonstrated psychoactivity in humans (for review (Raetsch 2005)). Even though there is a huge need for new molecules in mental health, this reservoir of knowledge remains greatly untapped. One of the main reasons is probably the lack of a good in vivo system allowing testing of psychoactive efficacy of complex mixtures of unknown composition. Ethnobotanical reports on a specific plant often differ on plant species/subspecies/harvest but also on mode of preparation and administration which all generate a number of imponderable parameters. Therefore, it is necessary to establish a 
system which would be capable of circumventing those problems. Ideally, the proposed system has to be flexible and sensitive enough to allow rapid and systematic screening of a big number of complex mixtures like crude plants extracts. In such a system, first pass screening could be done with minimally processed extracts like preparations made from dried powdered parts of a plant of interest. Subsequently, gradually refined mixtures could be tested the same way to eventually isolate the active compound(s).

Psychoactivity, unlike other physiologic activities, needs to be tested in an organism with an elaborate nervous system. Classical animal models like rodents are expensive, which is a major drawback for first-pass screening, and drug administration can be challenging. We used instead zebrafish larvae which have been successfully used for drug screening and are amenable to high throughput (Rennekamp and Peterson 2015). An adult couple can yield weekly several hundred eggs, which develop rapidly and externally (Kimmel et al. 1995). At 5 days post-fertilization (dpf), the fully developed little fish will exhibit a range of sophisticated behaviors like escaping predators and catching prey (Muto and Kawakami 2013). Drugs can be simply added to the water in which animals swim for the entire duration of the experiment. Uniform exposure and drug delivery from animal to animal can be assumed, even if there is still little known about pharmacokinetics of psychoactive compounds in zebrafish (MacRae and Peterson 2015).

We based our screening assay on a quantifiable, strong behavior: the response of fish to light and dark conditions which is already present in young larvae (MacPhail et al. 2009). Fish swim considerably less when exposed to strong light and significantly more when in the dark. After an abrupt light change, animals adjust activity by drastically decreasing swimming when the light is turned on and drastically increasing it when the light is turned off. It has been referred to as the photomotor response (PMR) (Kristofco et al. 2015). PMR or the short post-transition period after a light change is followed by a period of habituation which can be repeatedly interrupted by switching light conditions again, thus creating a highly predictable light-dependent cyclic behavior. Remarkably, this strong behavior can be profoundly modified by known anxiogenic/convulsive drugs like aconitine or pentylenetetrazole (PTZ) (Ellis et al. 2012; Ellis and Soanes 2012). We could reliably and reproducibly elicit swimming alterations over several light and dark cycles with a set PTZ concentration of $7.5 \mathrm{mM}\left(\mathrm{PTZ}_{7.5}\right)$. $\mathrm{PTZ}_{7.5}$-altered swimming was maximal in post-transitions. (1) When turning the light on, we measured a huge increase in swimming or "hyperactivity" in opposition to the sharp decrease in activity seen in untreated control animals. (2) On the contrary, when turning the light off, we measured an immediate drastic decrease in activity resembling "freezing" in opposition to the stark increase in activity seen in untreated control animals. In addition to those two measures of anxiety, we assessed a third parameter: (3) light-dependent center avoidance. PTZ $_{7.5}$ application elicited no center avoidance in light and provoked it in dark in complete opposition with the behavior of untreated control larvae which were avoiding the center in light conditions only. We hypothesized that those three defined parameters of the PTZ 7.5 -altered swimming could be used for measuring efficacy of a psychoactive compound which would be present in the water as a highly purified synthetic molecule or as a part of a complex mixture. An efficient molecule would reverse at least one or more of the three parameters of the $\mathrm{PTZ}_{7.5}$-altered swimming behavior in a concentrationdependent manner.

To validate this in vivo system, we tested aqueous crude extracts of a fairly well-studied psychoactive plant: Valeriana officinalis. Commonly called Valerian (Val), its root extracts are widely used as dietary supplement to treat insomnia and anxiety (Fugh-Berman and Cott 1999). Small clinical studies have yielded controversial results on its efficacy (Bent et al. 2006; Fernandez-San-Martin et al. 2010; Taibi et al. 2009). In vivo studies mostly agree on its anxiolytic (Murphy et al. 2010) and anti-convulsive (Rezvani et al. 2010) but not sedative (Hattesohl et al. 2008) properties. In vitro assays showed that crude extracts and isolated constituents like valerenic acid (Benke et al. 2009), alkaloids, and lignans can interact with $\mathrm{GABA}_{\mathrm{A}}$ (Cavadas et al. 1995), glutamate (Del Valle-Mojica et al. 2011a), adenosine (Lacher et al. 2007), and serotonin (Dietz et al. 2005) receptors. This argues for synergistic action of the more than 150 biomedically relevant chemicals which have been isolated from Val crude extracts (Patočka 2010). More relevant to this study is another major constituent, valeric acid, which led to the synthesis of an analog, valproic acid (VPA), which is the primarily prescribed mood stabilizer for bipolar disorders (Chiu et al. 2013). We used VPA to validate our behavioral screening assay and established a dose-response profile with four different concentrations. We proceeded likewise with Val root crude extracts. Our results clearly showed a significant concentration-dependent reversal of all three assessed parameters of the $\mathrm{PTZ}_{7.5}$-altered swimming with both VPA and Val. In addition, with higher concentrations of VPA-alone treatments, we found lightindependent hypoactivity. This was reminiscent of sedation induced by higher dosage that has been extensively documented in animals (Berghmans et al. 2007) and humans (Chateauvieux et al. 2010), thus validating the relevance of the usage of this lower vertebrate for psychoactivity testing. Furthermore, we found that Val, at all concentrations tested, consistently elicited hyperactivity in a PTZ-independent manner, which might be accounted for by one or more of the multiple active compounds potentially present in the complex mixture that we tested.

To confirm our behavioral results with Val extracts, we tracked changes in neuronal activity in the brain of treated 
larvae. To do so, we analyzed the gene expression patterns of a small set of neural activity upregulated genes. Those genes were previously shown to be transcriptionally upregulated in response to increased brain synaptic activity in general and to PTZ treatments in particular (Baxendale et al. 2012). We chose $c$-fos, the gold standard for detecting synaptic activity (Zhang et al. 2002); npas4a, involved in regulating excitatoryinhibitory balance within neural circuits (Bloodgood et al. 2013; Lin et al. 2008; Spiegel et al. 2014); and the neurotrophic factor $b d n f$, a putative downstream target of both $c$-fos and npas 4a (Greenberg et al. 2009; Lin et al. 2008). We analyzed how the different treatments affected the transcription of all three genes, first by whole-mount in situ hybridization (WISH) to establish changes in expression domain in larval brains and second by qPCRs to quantify the changes. We showed strong transcriptional down-regulation of synaptic activity genes in animals co-treated with Val and $\mathrm{PTZ}_{7.5}$ for all three genes. We also found the transcription of $c$-fos to be upregulated in larvae treated with Val-alone when comparing to untreated control animals. Therefore, our molecular data fully corroborated and consolidated our behavior results. In addition, we showed for the first time that Val strongly regulates transcription of neuronal activity upregulated genes in the brain, thus providing the first molecular evidence of the psychoactive efficacy of a complex mixture minimally prepared from plant crude extracts.

Taken together, our coupled behavioral-molecular approach demonstrated the sensitivity of our in vivo system in detecting psychoactivity, even in a complex mixture of unknown composition, namely, an aqueous plant crude extract. Therefore, we are providing a means for systematic and highthroughput testing of strong ethnobotanical psychoactive candidates in the quest of new psychiatric drugs.

\section{Materials and methods}

\section{Fish strain/care/husbandry}

For breeding, we used an original strain of zebrafish (Danio rerio) known as "TAB-5" made from a hybrid cross between fish from two of the most commonly used zebrafish lines, namely, Tübingen, TUB, (Haffter et al. 1996) and AB (Streisinger et al. 1981). TAB-5 was first isolated in 1997 and maintained without ever introducing any other outside genetic diversity. At least once a year, pools of siblings were crossed and their offspring raised to generate the next generation. A strong mating pair was used to derive the NHGR-1 line which has been sequenced to a depth of $\sim 50 \times$, and all polymorphisms have been mapped (LaFave et al. 2014). All of our husbandry protocols are in accordance with standard procedures (Westerfield 1993) and the IACUC-authorized protocol (no. A880213). Fish were raised at $28^{\circ} \mathrm{C}$ on $14: 10$ - h light/dark cycles on a recirculating system (Techniplast ${ }^{\circledR}$ ). Water supplied to the system was filtered by reverse osmosis (Siemens) and maintained at a neutral pH ( 7.0-7.5) and stable conductivity $(\sim 1000 \mu \mathrm{S} / \mathrm{cm})$ by adding Instant Ocean ${ }^{\circledR}$ sea salts. We refer to it herein as system water (SW). Fertilized embryos were raised in SW at $28{ }^{\circ} \mathrm{C}$ on $14: 10-\mathrm{h}$ light/dark cycles, and larvae with inflated swim bladders (that we used as an internal readout for good health) and no obvious abnormalities were selected for subsequent experiments.

\section{Chemicals}

PTZ and VPA were obtained from Sigma-Aldrich. Stock solutions were prepared in SW and stored at $4{ }^{\circ} \mathrm{C}$ for less than 2 weeks. We tested serial dilutions of PTZ ranging from 2 to $10 \mathrm{mM}$ and empirically determined that $\mathrm{PTZ}_{7.5}$ was optimal for triggering a reproducible PTZ-altered swimming in larvae. We used $\mathrm{PTZ}_{7.5}$ in all subsequent experiments. We established a dose-response profile for VPA with four concentrations (VPA $=0.5,1,2$, and $3 \mathrm{mM}$ ) based on previous work done in zebrafish (Berghmans et al. 2007; Ellis and Soanes 2012). We established survival curves for both PTZ $_{7.5}$ and VPA for all the above mentioned concentrations, and we did not see significant effects for at least $24 \mathrm{~h}$, which exceeded by far the timeline of our assay (data not shown), thus validating the assay for freedom from toxic influence of the test system.

\section{Valerian root extract preparation}

We exclusively prepared aqueous plant extracts to avoid ethanol residues, which could affect the animals and confound results (Parker et al. 2014). Preparations were always made ad hoc to avoid degradation of the solutions. We purchased (from Pacific Botanicals, Grants Pass, OR) dry powdered valerian roots certified organically grown and minimally processed as described by the seller (www.pacificbotanicals.com). We acquired a large enough quantity to perform all needed experiments in order to avoid possible harvest-to-harvest variations which have been described previously (Patočka 2010). The dry powder was kept in a light-opaque tightly sealed container at $+4{ }^{\circ} \mathrm{C}$ and handled with extreme care to avoid contamination. We prepared the extracts following a previously published method (Del Valle-Mojica et al. 2011b; TorresHernández et al. 2015). In brief, we prepared ad hoc a stock solution $(=100 \mathrm{mg} / \mathrm{ml})$ of dry powdered valerian roots which we magnetically stirred into SW in a covered beaker at RT $\left(25^{\circ} \mathrm{C}\right)$ for $1 \mathrm{~h}$. Next, we filtered the solution through coarse paper to remove the residual suspensions and to homogenize the extract. We diluted further with SW to the desired concentration. To establish a dose-response profile for Val, we used previously reported work in zebrafish adults (Torres-Hernández et al. 2015). We tested four concentrations $(\mathrm{Val}=1,2.5,5$, and $7 \mathrm{mg} / \mathrm{ml})$. We also 
established survival curves with all of those concentrations, and we did not see significant effects for at least $24 \mathrm{~h}$ which exceeded by far the timeline of our assay (data not shown), thus again validating the assay for freedom from toxic influence of the test system.

\section{Dark/light response behavioral assay in larvae}

\section{Plate setup and drug administration}

For each behavioral experiment, we recorded 48 animals in parallel (= one 48 -well plate (CELLSTAR $\left.{ }^{\circledR}\right)$ with one larva/ well) and performed independent triplicates for all treatments. Preliminary testing confirmed that there was no bias induced by larvae occupying a specific location in the plate (data not shown), thus freeing us from having to randomize fish location according to treatment designation throughout experiments. We collected eggs from group spawning $(\sim 5-7$ females with 8-10 males) of wild-type animals (TAB-5). We raised embryos in clean SW that we replaced daily and maintained them in a light-cycled incubator (14:10 h light/dark) set at $28{ }^{\circ} \mathrm{C}$. To allow animals to adapt to the new environment, we plated one single healthy 5 -dpf larva in each well in $450 \mu \mathrm{SW} 1$ day prior to recording. Next day, we checked the health of the animals before topping off wells to $500 \mu \mathrm{l}$ with SW or SW with drugs (PTZ, VPA, or Val) to the desired concentration. When determining the optimal PTZ concentration to induce a reproducible altered swimming, we split the plates in two with the three top rows containing untreated larvae (Unt, $n=3 \times 8=24$ ) and the three bottom rows containing larvae treated with the PTZ concentration under study (PTZ, $n=24)$. We averaged swimming distances per larva from the triplicate independent experiments (Unt, $n=72$, and PTZ, $n=72$ ).

For each tested concentration of VPA and Val, we systematically measured in parallel the swimming activity of (1) untreated larvae, (2) $\mathrm{PTZ}_{7.5}$-alone-treated larvae, (3) compoundalone-treated larvae, and (4) $\mathrm{PTZ}_{7.5}+$ tested compoundtreated larvae. We averaged the results from the triplicate independent experiments and reported swimming distance $/ \mathrm{min} /$ larva for each treatment as exemplified for Val $1 \mathrm{mg} / \mathrm{ml}=\mathrm{Val}_{1}$ (Unt $n=24 ; \mathrm{PTZ}_{7.5} n=24 ; \mathrm{Val}_{1} n=48$; and $\mathrm{PTZ}_{7.5}+\mathrm{Val}_{1}$ $n=48$ ). Once we added the drugs, we immediately put the plate into the ZebraBox (Viewpoint, France) and started the recording ( $\sim 3 \mathrm{~min})$. For the first $27 \mathrm{~min}$, larvae were in the dark to adapt to the light condition. Next, we submitted larvae to four successive cycles of alternating $10 \mathrm{~min}$ of bright light (L) and complete dark (D).

\section{Swimming activity tracking}

We empirically partitioned the recording and reporting of larval activity according to three swim speeds: slow (S1), sustained (S2), and fast (S3), which we determined based on prior reports (Ellis et al. 2012), preliminary swim speed analyses, and manufacturer's recommendation. Slow swim speeds $(\mathrm{S} 1<0.2 \mathrm{~cm} / \mathrm{s})$ were reporting minimal activity of larva which was at the limit of detection by the recording device. Fast swim speeds ( $\mathrm{S} 3>2 \mathrm{~cm} / \mathrm{s}$ ) were relatively rarely seen, always short-lasting, and corresponded to intermittent powerful larval accelerations. Sustained swim speeds $(0.2 \mathrm{~cm} / \mathrm{s}<\mathrm{S} 2<2 \mathrm{~cm} / \mathrm{s})$ were observed during the remainder of larval activity. We further partitioned the recording of swimming activity according to the location in the well (total well diameter, $d_{o}=1 \mathrm{~cm}$ ). A virtual inner open space was delimited (inner circle, $\mathrm{d}_{\mathrm{i}}=0.5 \mathrm{~cm}$ ), and traveled distances were designated as total distances when considering the entire well as opposed to inner distances when considering solely the inner open space.

\section{Statistical analyses}

\section{Behavioral assay statistical analyses}

We analyzed averaged total distances traveled per larva from the triplicate experiments using GraphPad Prism (v.6) and plotted them vs. a time axis, displaying the entire time-course of the experiment. We included in all graphs the error bars which represent the mean \pm standard error of the mean (SEM). Further statistical analyses were performed using the software Stata (v.14). We carried out a first set of parametric analyses using the mixed command in Stata. We analyzed total traveled distances in two swim speeds (S2 and S3) for all VPA and Val concentrations tested segregated by light patterns. First, we analyzed the compiled distances traveled during the entire 10 min of all dark periods $(D=D 1+D 2+D 3+D 4)$ or all light periods $(\mathrm{L}=\mathrm{L} 1+\mathrm{L} 2+\mathrm{L} 3+\mathrm{L} 4)$. Next, we distinguished posttransitions (= first minute after a light change), from all four light to dark (L/D) and all four dark to light $(\mathrm{D} / \mathrm{L})$ changes. And, finally, we distinguished all compiled non-transitions in light or in dark periods (= remaining 9 min of all light or all dark periods, respectively). We analyzed the same way inner distances but only for post-transitions. For this first set of analyses, we used a linear regression model with categorical predictors with random intercept. The parameter estimation was performed using the multilevel linear regression model approach (Leyland 2004). This model allowed us to control the effect of the correlation among the number of fixed repeated measures on the same larvae. Based on this model, we made an assessment of the interaction between treatment and light pattern by performing six different comparisons at different time points: (1) untreated (Unt) vs. PTZ 7.5 (PTZ); (2) Unt vs. VPA and Unt vs. Val; (3) Unt vs. PTZ+VPA and Unt vs. PTZ+ Val; (4) PTZ vs. VPA and PTZ vs. Val; (5) PTZ vs. PTZ+ VPA and PTZ vs. PTZ+ Val; and (6) VPA vs. PTZ+ VPA and Val vs. PTZ + Val. Selected results are discussed in the "Results" section and summarized in Supplementary Tables (Table 1 for 
PTZ treatments corresponding to Fig. 1, Table 2 for VPA treatments corresponding to Fig. 2, and Table 6 for Val treatments corresponding to Fig. 3).

In order to analyze individual transitions for each treatment, we performed a second set of parametric analyses. Due to the heterogeneity of variances found after the Bartlett's tests, we performed modified Brown and Forsythe tests which are several $t$ tests with unequal variances which we performed for each transition and for each treatment. To control the experimentwise type I error that resulted from those multiple $t$ tests, we used the $F$ Fisher probability distribution as recommended by Tamhane and Bechhofer (Tamhane and Bechhofer 1979).
Selected results are discussed in the "Results" section and summarized in Supplementary Tables (Tables 3, 4, and 5 for VPA corresponding to Fig. 2 and Tables 7, 8, and 9 for Val corresponding to Fig. 3). All statistical results from the separate analyses were consistent throughout experiments. Complete detailed results are available upon request.

\section{qPCR data statistical analysis}

After each run, $\Delta \mathrm{C}_{\mathrm{t}}$ was determined with the EcoStudy Software (Illumina) using two reference genes and normalized against the untreated sample. Fold change was calculated
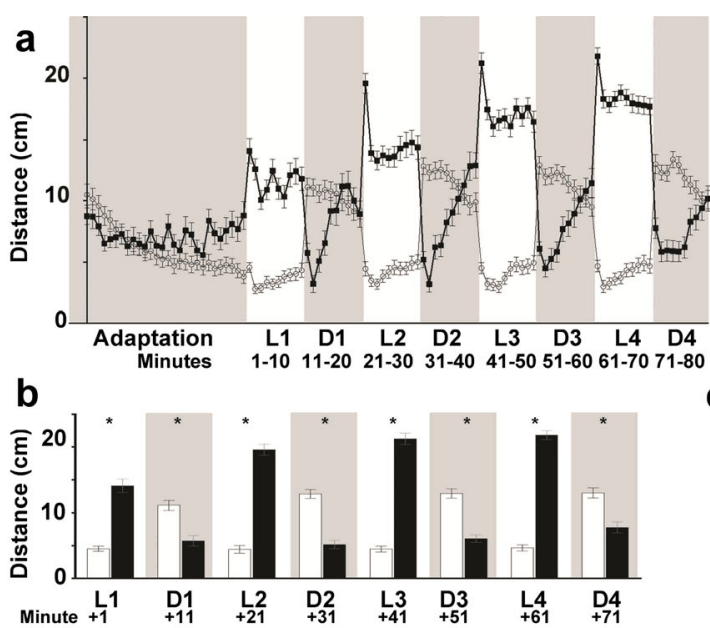

C
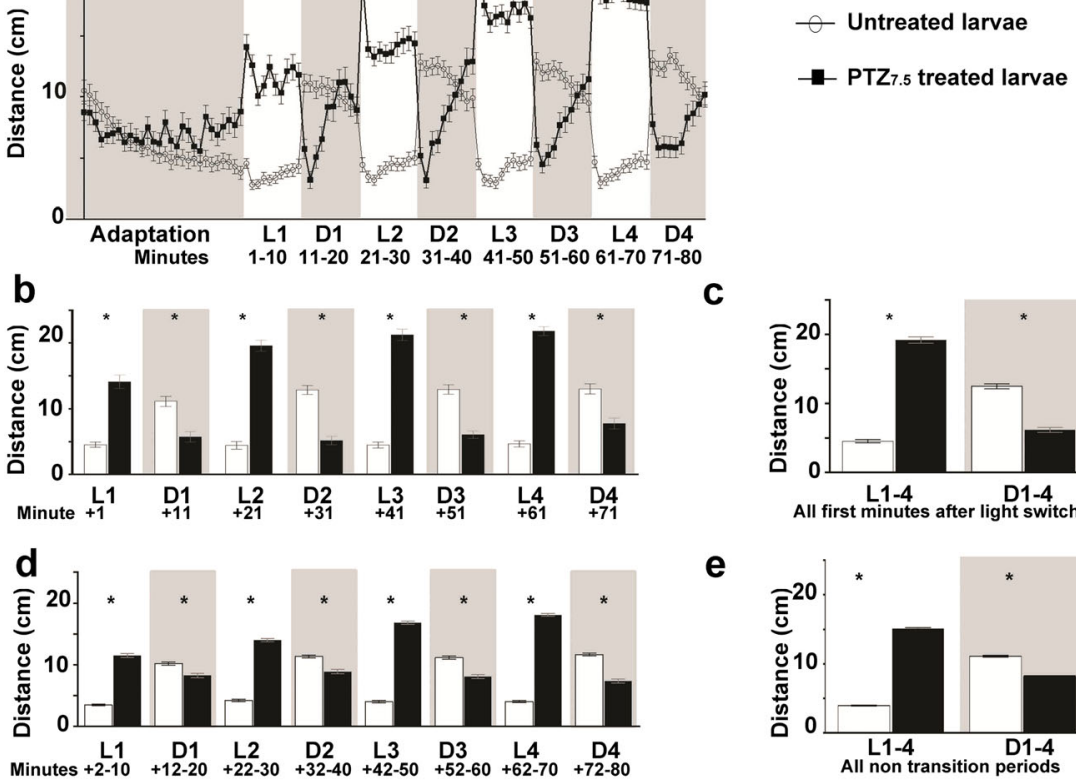
f
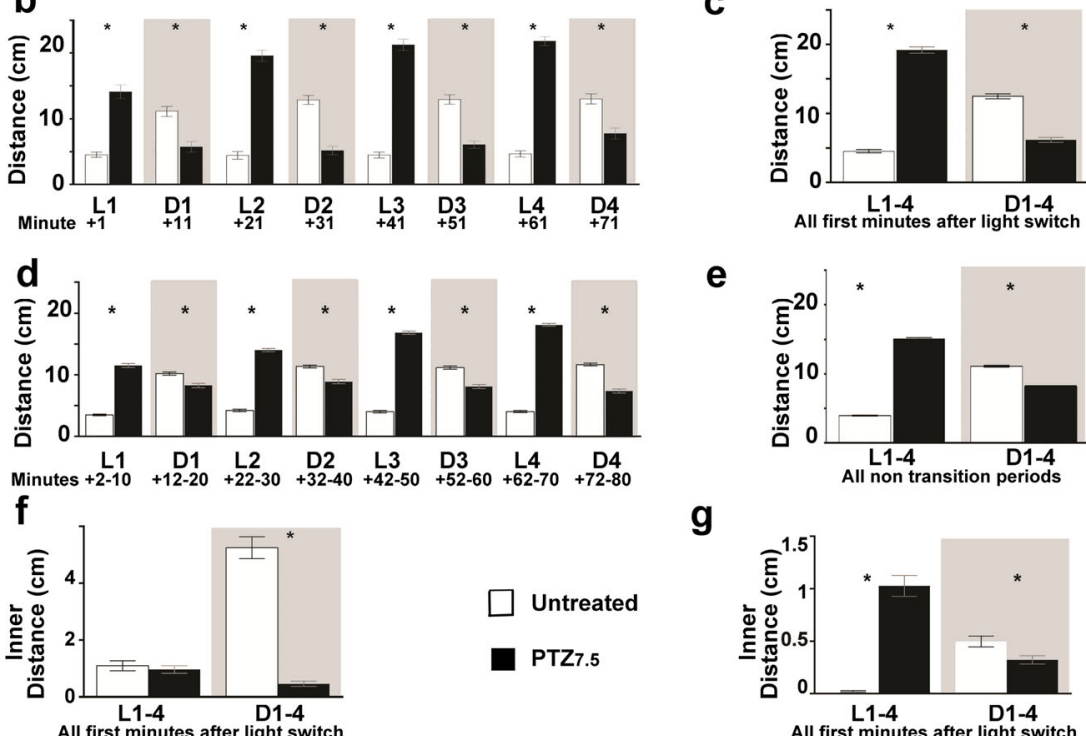

h

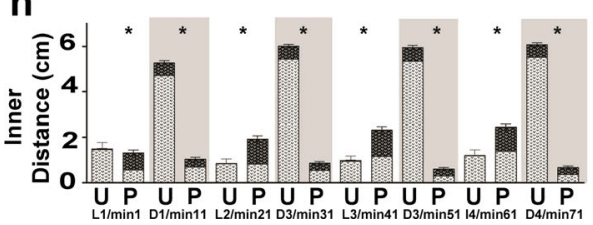

e

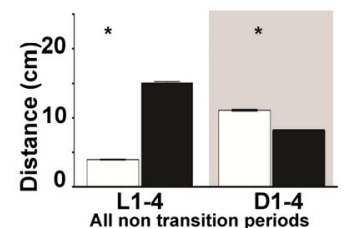

g

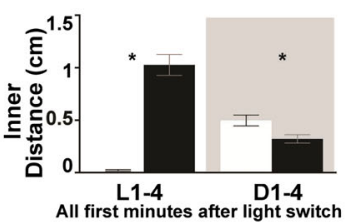

Swim speed S2: $0.2<\mathrm{S} 2<2 \mathrm{~cm} / \mathrm{s}$

Swim speed $\mathrm{S} 3: \mathrm{S} 3>2 \mathrm{~cm} / \mathrm{s}$

U: Untreated

P: PTZ7.5

Fig. $1 \mathrm{PTZ}_{7.5}$ alters light-dependent swimming behaviors in zebrafish larvae. a Mean traveled distances $(\mathrm{cm})$ by untreated $(-0-)$ and $\mathrm{PTZ}_{7.5^{-}}$ treated (-) larvae reported minute by minute for the entire $80 \mathrm{~min}$ of recording. After an adaptation period to dark (gray box), larvae were submitted to four successive 10-min alternating light (L1-L4: white zones) and dark periods (D1-D4: gray zones). b Distances traveled in all successive post-transitions (=first minutes after a light switch) by untreated $(\square)$ and PTZ $_{7.5}$-treated larvae $(\square)$. c Distances traveled in cumulative post-transitions in light ( $L 1-4$, white boxes) and in dark $(D$
1-4, grey boxes). d Distances traveled during all successive nontransitions (= remaining $9 \mathrm{~min}$ of each light or dark periods). e Distances traveled in compiled non-transitions. f Inner distances traveled in swim speed S2 $(0.2 \mathrm{~cm} / \mathrm{s}<\mathrm{S} 2<2 \mathrm{~cm} / \mathrm{s})$ in compiled posttransitions. g Inner distances traveled in swim speed S3 $(>2 \mathrm{~cm} / \mathrm{s})$ in compiled post-transitions. $\mathbf{h}$ Inner distances traveled in all successive post-transitions in swim speed S2 (圆) and S3 (盛). Error bars representing SEM. ${ }^{*} p$ values $<0.001$ (detailed values are presented in Supplementary Table 1) 


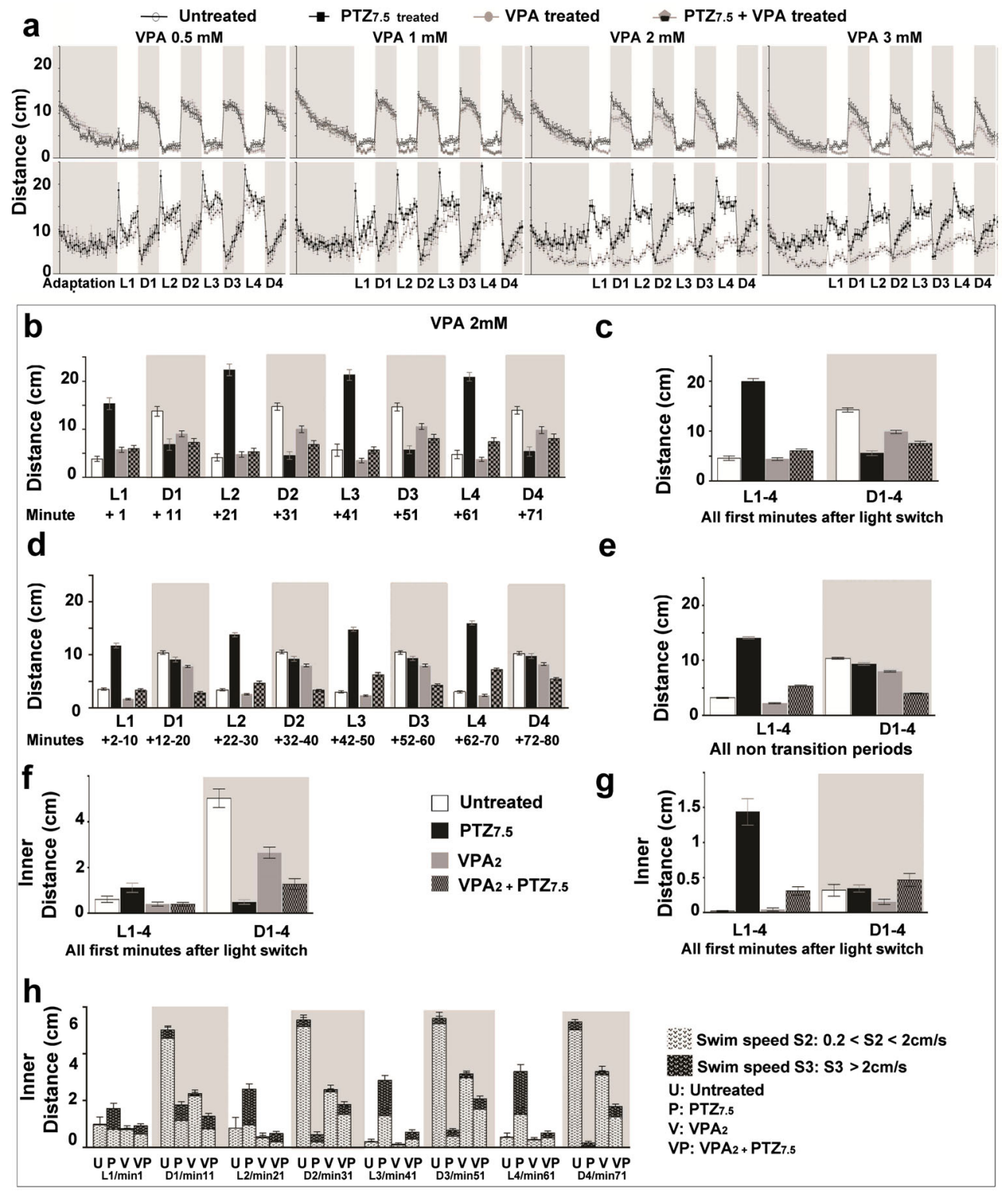

Fig. 2 Valproate reverses $\mathrm{PTZ}_{7.5}$-altered light-dependent swimming behavior. a Mean traveled distances $(\mathrm{cm})$ by untreated $(-0-)$ and VPAalone-treated $(-)$ larvae in top panels, and by $\mathrm{PTZ}_{7.5}$-alone-treated $(-\mathbf{-})$ and VPA $+\mathrm{PTZ}_{7.5}$-co-treated (-) larvae in bottom panels. Larvae were treated with increasing VPA concentrations: $0.5 \mathrm{mM}\left(\mathrm{VPA}_{0.5}\right.$, left column), $1 \mathrm{mM}$ ( $\mathrm{VPA}_{1}$, second column), $2 \mathrm{mM}\left(\mathrm{VPA}_{2}\right.$, third column), and $3 \mathrm{mM}\left(\mathrm{VPA}_{3}\right.$, fourth column). b Distances traveled during all successive post-transitions by untreated ( $\square$ ), PTZ $_{7.5}$-alone-treated ( $\square$ ), $\mathrm{VPA}_{2}$ alone ( $\left(\right.$ ), and $\mathrm{PTZ}_{7.5}+\mathrm{VPA}_{2}$-co-treated larvae (㽞). c Distances traveled during cumulative post-transitions. d Distances traveled during all successive non-transitions (= remaining 9 min of each light or dark

using the $2^{-\Delta \Delta C}$ method (Livak and Schmittgen 2001), and level of expression in untreated animals was defined as 1 . Results were compiled using GraphPad Prism. Errors bars represented the $95 \%$ confidence interval, and statistical difference was tested with the non-parametric KruskalWallis test. periods). e Distances traveled during compiled non-transitions. f Inner distances traveled in swim speed $\mathrm{S} 2(0.2 \mathrm{~cm} / \mathrm{s}<\mathrm{S} 2<2 \mathrm{~cm} / \mathrm{s})$ during compiled post-transitions. $\mathbf{g}$ Inner distances traveled in swim speed S3 ( $>2 \mathrm{~cm} / \mathrm{s}$ ) during compiled post-transitions. h Inner distances traveled during all compiled post-transitions in swim speed S2 (國) and S3 (-4) by untreated $(U), \mathrm{PTZ}_{7.5}$-alone-treated $(P), \mathrm{VPA}_{2}$-alone-treated $(V)$, and $\mathrm{VPA}_{2}+\mathrm{PTZ}_{7.5}$-co-treated $(V P)$ larvae. Error bars represent SEM. Symbols for significant $p$ values were omitted for clarity but are discussed in the "Results" section and detailed in Supplementary Tables 2, 3, 4, and 5

\section{Whole-mount in situ hybridization}

WISH was performed as described (Thisse and Thisse 2008). All antisense probes were prepared from plasmids kindly gifted by Dr. Vincent Cunliffe (Baxendale et al. 2012). Imaging was performed with an inverted Axiovert (Zeiss) equipped 


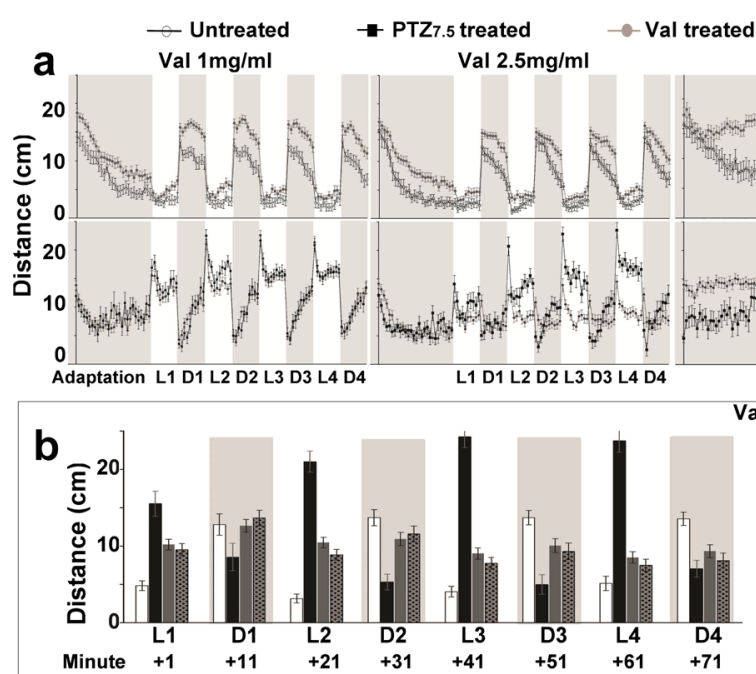

$-\mathrm{PTZ} 7.5+$ Val treated

Val $5 \mathrm{mg} / \mathrm{ml}$

Val $7 \mathrm{mg} / \mathrm{ml}$

d

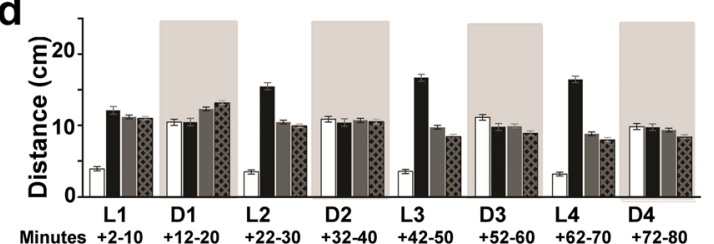

f

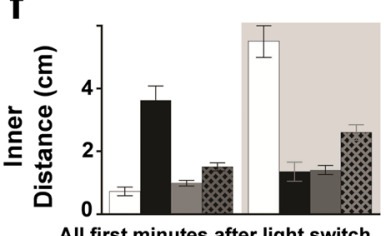

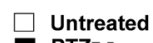

- PTZ7.5

- Val5

Val5+PTZ7.5 h

All first minutes after light switch

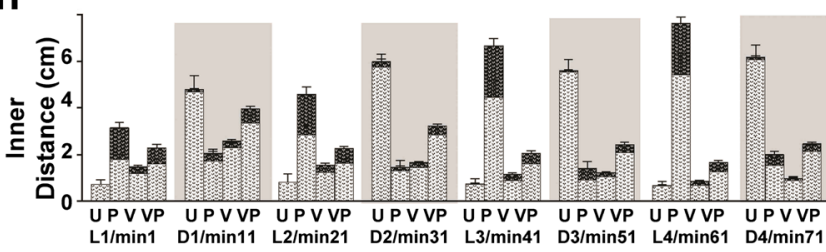

L1 D1 L2 D2 L3 D3 L4 D4 L1 D1 L2 D2 L3 D3 L4 D4

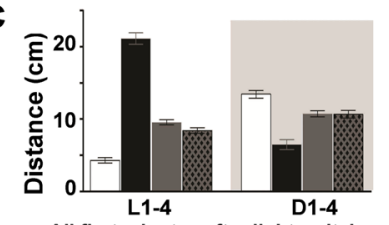

e
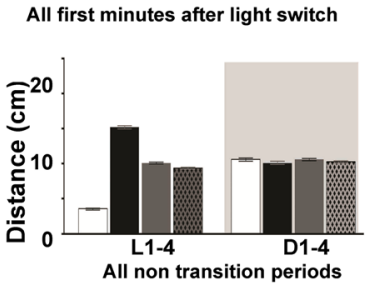

9

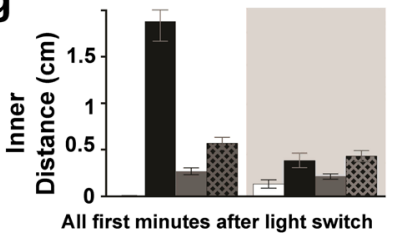

Fig. 3 Valerian extract (Val) reverses the $\mathrm{PTZ}_{7.5}$-altered light-dependent swimming behavior. a Mean traveled distances $(\mathrm{cm})$ by untreated (瞽) and Val-alone-treated (-O-) larvae in top panels, and by $\mathrm{PTZ}_{7.5}$-alone-treated $\left(-()\right.$ and $\mathrm{Val}+\mathrm{PTZ}_{7.5}$-co-treated (-) larvae in bottom panels. Larvae were treated with increasing Val concentrations: $1 \mathrm{mg} / \mathrm{ml}\left(\mathrm{Val}_{1}\right.$, left column), $2.5 \mathrm{mg} / \mathrm{ml}$ ( $\mathrm{Val}_{2.5}$, second column), $5 \mathrm{mg} / \mathrm{ml}$ ( $\left(\mathrm{Val}_{5}\right.$, third column), and $7 \mathrm{mg} / \mathrm{ml}$ (Val 7 , fourth column). b Distances traveled during all successive post-transitions by untreated (口), PTZ 7.5 -alonetreated $(\square), \mathrm{Val}_{5}$ alone $(\square)$, and $\mathrm{Val}_{5}+\mathrm{PTZ}_{7.5}$-co-treated larvae (㴦). c Distances traveled during compiled post-transitions. d Distances traveled during all compiled non-transitions. e Distances traveled during compiled non-transitions. f Inner distances traveled in swim speed S2 $(0.20 \mathrm{~cm} / \mathrm{s}<\mathrm{S} 2<2 \mathrm{~cm} / \mathrm{s})$ during compiled post-transitions. g Inner distances traveled in swim speed $\mathrm{S} 3(>2 \mathrm{~cm} / \mathrm{s})$ during cumulative posttransitions. h Inner distances traveled during all successive posttransitions in swim speed $\mathrm{S} 2$ (四) and $\mathrm{S} 3$ (感) by untreated $(U), \mathrm{PTZ}_{7.5^{-}}$ alone-treated $(P), \mathrm{Val}_{5}$-alone-treated $(V)$, and $\mathrm{Val}_{5}+\mathrm{PTZ}_{7.5}$-co-treated $(V P)$ larvae. Error bars represent SEM. Symbols for significant $\mathrm{p}$ values were omitted for clarity but are discussed in the "Results" section and detailed in Supplementary Tables 6, 7, 8, and 9 with AxioCam. Acquisitions were done using the AxioVision software. Final figures were assembled in Photoshop. The total number of WISH-stained animals for each antisense probe were as follows: $c$-fos (Unt $n=22, \mathrm{PTZ}_{7.5} n=23, \mathrm{Val}_{5}$ $\left.n=42, \mathrm{PTZ}_{7.5}+\mathrm{Val}_{5} n=29\right) ; b d n f\left(\mathrm{Unt} n=23, \mathrm{PTZ}_{7.5} n=33\right.$, $\left.\mathrm{Val}_{5} n=29, \mathrm{PTZ}_{7.5}+\mathrm{Val}_{5} n=30\right) ; \operatorname{npas} 4 a\left(\mathrm{Unt} n=24, \mathrm{PTZ}_{7.5}\right.$ $n=30, \mathrm{Val}_{5} n=32, \mathrm{PTZ}_{7.5}+\mathrm{Val}_{5} n=32$ ); gbr2 (Unt $n=20$, $\left.\mathrm{PTZ}_{75} n=31, \mathrm{Val}_{5} n=39, \mathrm{PTZ}_{75}+\mathrm{Val}_{5} n=18\right)$; and gabral (Unt $n=27, \mathrm{PTZ}_{7.5} n=28, \mathrm{Val}_{5} n=34, \mathrm{PTZ}_{7.5}+\mathrm{Val}_{5} n=30$ ).

\section{Quantitative PCRs}

Total RNA was extracted from pools of whole larvae ( $6 \mathrm{dpf}, n$ 20) using RNeasy ${ }^{\circledR}$ Plus Universal Mini Kit (Qiagen) following manufacturer's protocol. Three biological samples/ treatment were made from three independent behavioral assays. RNA concentration was determined (NanoPhotometer P-Class, Implen) and cDNAs synthesized with $2 \mu \mathrm{g}$ of RNA with SuperScript II Reverse Transcriptase (Invitrogen). 

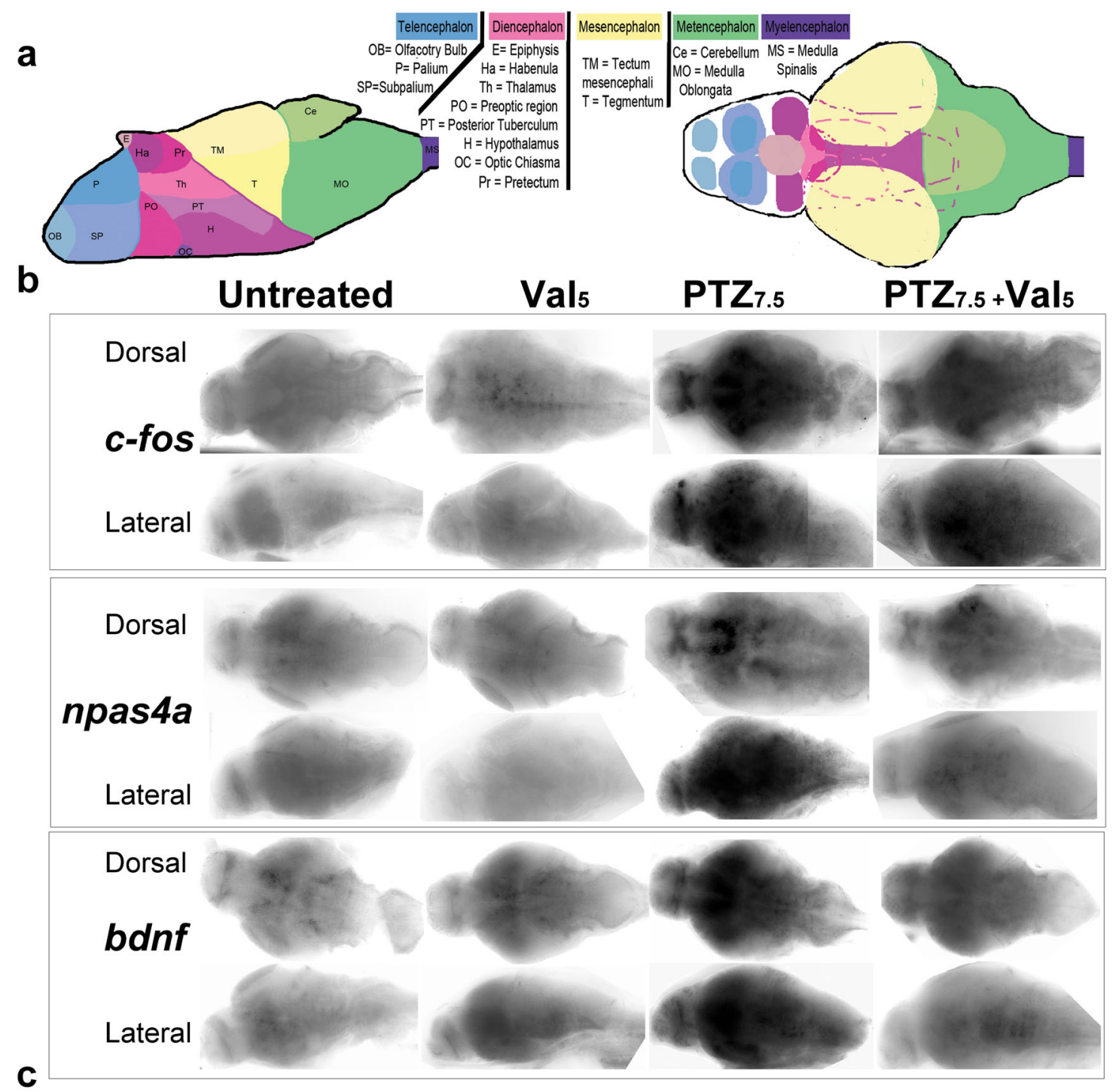
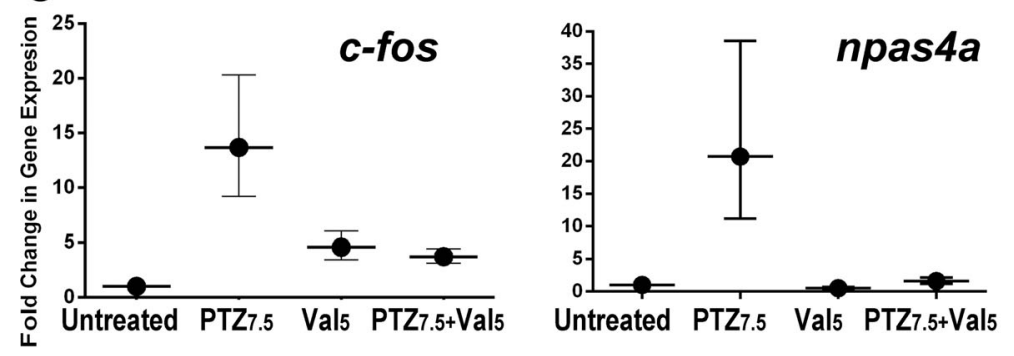

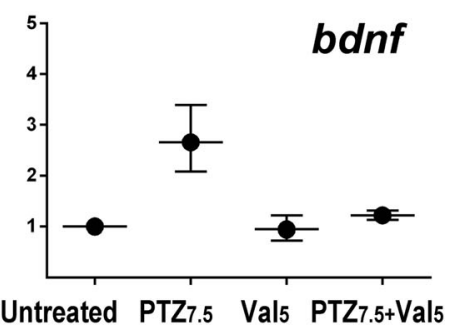

third, and fifth rows) and lateral views (second, fourth, and sixth rows). Representative untreated (first column), $\mathrm{Val}_{5}$-alone-treated (second column), $\mathrm{PTZ}_{7.5}$-alone-treated (third column), and $\mathrm{PTZ}_{7.5}+\mathrm{Val}_{5}$-cotreated (fourth column) larvae are shown. Antisense probes were used against $c$-fos (two top rows), npas4a (two middle rows), and bdnf (two bottom rows). $\mathbf{c}$ PCR measures of transcripts of $c$-fos (left panel), npas 4 a (middle panel), and bdnf (right panel). Basal expression was set in untreated $(=1)$ and fold change measured in larvae which had been exposed to $\mathrm{PTZ}_{7.5}$-alone, $\mathrm{Val}_{5}$-alone, or $\mathrm{PTZ}_{7.5}+\mathrm{Val}_{5}$. (-) 50 microns in b. Error bars represent standard deviations (SD) in c

R-TGGTCGTTCGTTTGAATCTCAT; elongation factor 1 alpha subunit (efla) F-CTGCCAGTGTTGCCTTCGT and 
R-CCTTGCGCTCAATCTTCCA; brain-derived neurotrophic factor (bdnf) F-TCGAAGGACGTTGACCTGTATG and R-TGGCGGCATCCAGGTAGT, peptide $Y Y a$ (Pyya) F-TCCTCATCTGCGTGCTTCTGT and R-GCGGTGTAA TATTTGGCGAGTT; GABAa receptor alphal (gabra1) F - T C A G G C A G A G C T G G A A G A T a n d R-TGCCGTTGTGGAAGAACGT; $c$-fos F-AACTGTCAC G G C G A T C T C T T and R-G C A G G C A T G TATGGTTCAGA; and npas $4 a$ F-ATGGGTCT GGTTTACATGG and R-CTTGTCTGGGTTGAGAG GAAC. Final primer concentrations were determined experimentally: $0.1 \mu \mathrm{M}$ for bdnf; $0.3 \mu \mathrm{M}$ for pyya, gabral, and gbrg2; and $0.5 \mu \mathrm{M}$ for c-fos and npas4a. Each gene along with two reference genes ( $\beta$-actin $0.1 \mu \mathrm{M}$ and efla $0.1 \mu \mathrm{M}$ ) was evaluated in parallel runs in an Eco ${ }^{\mathrm{TM}}$ Real-Time PCR machine (Illumina). Technical triplicates with three biological samples of all the different treatments were evaluated for each gene.

\section{Results}

\section{PTZ $_{7.5}$ alters light-dependent swimming behavior}

We first assessed the larval light-dependent swimming activity and aimed at reproducibly altering it with PTZ application. To do so, we set up 48-well plates with one animal/well and treated half of them with a set concentration of PTZ, while leaving the other half untreated. Immediately after PTZ addition, we placed animals in the dark inside the recording device to measure the traveled distance/minute/larva in 48 parallel recordings. After an additional $27 \mathrm{~min}$, we submitted larvae to 4 cycles of alternating light and dark periods of $10 \mathrm{~min}$ each. We divided the recording of all swimming activity according to three experimentally determined swim speeds (S1, $\mathrm{S} 2$, and S3). We calculated and represented means for the entire duration of the experiment. A highly reproducible light-dependent swimming pattern emerged for all swim speeds (S2 shown in Fig. 1a, S1 and S3 not shown). Untreated larvae $(-0)$ displayed low activity when exposed to light (L1 to L4 white boxes, Supplementary Table 1, Unt $=4.02 \mathrm{~cm} / \mathrm{min}$ ) which was nearly tripled when they were exposed to dark (D1 to D4 gray boxes, Unt $=11.25 \mathrm{~cm} / \mathrm{min}$ ). All tested PTZ concentrations altered significantly the swimming behavior (data not shown), but with PTZ $7.5 \mathrm{mM}$ $\left(=\mathrm{PTZ}_{7.5}\right)$, we could consistently trigger a quasi-opposite light-dependent swimming pattern. $\mathrm{PTZ}_{7.5}$-treated larvae (Fig. 1a-e and Supplementary Table 1) displayed an overall high activity when exposed to light (PTZ $=15.52 \mathrm{~cm} / \mathrm{min}$ ) which was lowered by half when they were exposed to dark (PTZ $=7.96 \mathrm{~cm} / \mathrm{min}$ ). Differences were highly significant in light and dark periods. Furthermore, differences were maximal during the first minute immediately following a light change in all successive post-transitions (Fig. 1b). In cumulative post-transitions (Fig. 1c) during light periods, untreated larvae traveled $4.54 \mathrm{~cm} / \mathrm{min}$ vs. $19.17 \mathrm{~cm} / \mathrm{min},(p<0.001)$ for PTZ $_{7.5}$-treated larvae which were exhibiting strong hyperactivity. On the contrary, during dark periods, PTZ $_{7.5}$-treated animals were freezing instead of increasing activity like untreated larvae $(\mathrm{Unt}=12.47 \mathrm{~cm} / \mathrm{min}$ vs. $\mathrm{PTZ}=6.19 \mathrm{~cm} / \mathrm{min}, p<0.001)$. This remained true in non-transitions (Fig. 1e) with smaller but still highly significant differences during light periods (Unt $=3.96 \mathrm{~cm} / \mathrm{min}$ vs. $\mathrm{PTZ}=15.12 \mathrm{~cm} / \mathrm{min}$ ) and during dark periods $(\mathrm{Unt}=11.11 \mathrm{~cm} / \mathrm{min}$ vs. $\mathrm{PTZ}=8.16 \mathrm{~cm} / \mathrm{min})$. Thus, with PTZ $_{7.5}$, we profoundly altered the light-dependent swimming activity and elicited an opposite response to change in light conditions as compared to untreated controls.

In addition, we measured a well-accepted behavioral criterion for anxiety: avoidance of open space. To do so, we measured inner-traveled distances during post-transitions only as larvae were traveling very little to the center during nontransitions (data not shown). We found a clear lightdependent center avoidance in untreated larvae which was significantly altered by $\mathrm{PTZ}_{7.5}$ treatments in a least one of the swim speeds (S2 shown in Fig. 1f; S3 shown in Fig. 1g; cumulative S2 and S3 shown in Fig. 1h; S1 not shown). During light periods, untreated larvae were avoiding the center in both swim speeds, but $\mathrm{PTZ}_{7.5}$-treated animals did not in $\mathrm{S} 3$ (compare in Fig. $1 \mathrm{~g}$, Unt $=0.02 \mathrm{~cm} / \mathrm{min}$ vs. $\mathrm{PTZ}=1.03 \mathrm{~cm} /$ $\min , p<0.001)$. When exposed to dark, in both $\mathrm{S} 2$ and $\mathrm{S} 3$ and in all post-transitions (Fig. 1h S2 and S3 cumulative), untreated animals increased activity in the center, as opposed to PTZ $_{7.5}$-treated animals which decreased it. Differences were maximal in the sustained swim speed S2 (Fig. 1f, Unt $=5.18$ $\mathrm{cm} / \mathrm{min}$ vs. PTZ $=0.46 \mathrm{~cm} / \mathrm{min}, p<0.001)$ but still highly significant in the fast swim speed S3 (Fig. $1 \mathrm{~g}, \mathrm{Unt}=0.57 \mathrm{~cm} / \mathrm{min}$ vs. $\mathrm{PTZ}=0.32 \mathrm{~cm} / \mathrm{min}, p<0.001)$. Thus, $\mathrm{PTZ}_{7.5}$ treatments were also clearly altering the light-dependent center avoidance. Unlike untreated larvae that were only traveling to the center in dark periods, $\mathrm{PTZ}_{7.5}$-treated larvae were only traveling to the center in light periods.

\section{Valproate reverses $\mathrm{PTZ}_{7.5}$-altered light-dependent swimming behavior}

Next, we aimed at validating the use of this $\mathrm{PTZ}_{7.5}$-altered light-dependent swimming behavior in zebrafish larva and proving its relevance for humans. To do so, we tested a well-described psychoactive synthetic molecule, valproic acid $($ valproate $=$ VPA $)$. First, we established a dose-response profile for VPA and successively tested four concentrations $\left(\mathrm{VPA}_{0}=0.5 \mathrm{mM}, \mathrm{VPA}_{1}=1 \mathrm{mM}, \mathrm{VPA}_{2}=2 \mathrm{mM}\right.$, and $\mathrm{VPA}_{3}=3 \mathrm{mM}$ ). For each VPA concentration, we recorded independent triplicate experiments of 48 larvae/plate set up as follows: 8 untreated, $8 \mathrm{PTZ}_{7.5}$-alone-treated, $16 \mathrm{VPA}$ - 
alone-treated, and $16 \mathrm{PTZ}_{7.5}+\mathrm{VPA}-\mathrm{co}-$ treated larvae. We plotted the means against time for each concentration (Fig. 2a, VPA ${ }_{0.5}$ left panels, $\mathrm{VPA}_{1}$ center left panels, VPA 2 center right panels, and $\mathrm{VPA}_{3}$ right panels). For clarity, we presented treatments pairwise: untreated with VPA alone (top row, $-0-$ and $-\mathbf{-}$, respectively) and $\mathrm{PTZ}_{7.5}$ alone with $\mathrm{PTZ}_{7.5}+$ VPA (bottom row, $\rightarrow$ and - , respectively). Across all concentrations of VPA, in light periods, overall distances traveled by untreated vs. VPA-alone-treated animals were not significantly different (Fig. 2a top panels, white boxes). However, in dark periods, animals treated with the two higher concentrations traveled less (gray boxes and Supplementary Table 2: Unt $=10.75 \mathrm{~cm} / \mathrm{min}$ vs. $\mathrm{VPA}_{2}=8.15 \mathrm{~cm} / \mathrm{min}$, $p<0.001 ; \mathrm{Unt}=9.02 \mathrm{~cm} / \mathrm{min}$ vs. $\mathrm{VPA}_{3}=5.63 \mathrm{~cm} / \mathrm{min}$, $p<0.001$ ), suggesting a concentration-dependent sedation.

Overall traveled distances by $\mathrm{PTZ}_{7.5}$-alone-treated larvae compared with distances traveled by $\mathrm{PTZ}_{7.5}+\mathrm{VPA}-\mathrm{Co}_{\text {-treated }}$ larvae were strongly reduced in all co-treatments and in a VPA concentration-dependent manner in light periods $\left(\mathrm{PTZ}_{7.5}=15.13 \mathrm{~cm} / \mathrm{min}\right.$ vs. $\mathrm{PTZ}_{7.5}+\mathrm{VPA}_{0.5}=12.53 \mathrm{~cm} / \mathrm{min}$, $p<0.002 ; \mathrm{PTZ}_{7.5}=15.12 \mathrm{~cm} / \mathrm{min}$ vs. $\mathrm{PTZ}_{7.5}+$ $\mathrm{VPA}_{1}=10.39 \mathrm{~cm} / \mathrm{min}, p<0.001 ; \mathrm{PTZ}_{7.5}=14.65 \mathrm{~cm} / \mathrm{min}$ vs. $\mathrm{PTZ}_{7.5}+\mathrm{VPA}_{2}=5.44 \mathrm{~cm} / \mathrm{min}, p<0.001 ; \mathrm{PTZ}_{7.5}=13.61 \mathrm{~cm} /$ min vs. $\mathrm{PTZ}_{7.5}+\mathrm{VPA}_{3}=6.07 \mathrm{~cm} / \mathrm{min}, p<0.001$ ), suggesting reversal of the hyperactivity. This was even more striking in post-transitions. Hyperactivity in light was reversed in all cotreatments and was reduced by nearly 3 -fold with the two higher VPA concentrations $\left(\mathrm{PTZ}_{7.5}=21.46 \mathrm{~cm} / \mathrm{min}\right.$ vs. $\mathrm{PTZ}_{7.5}+\mathrm{VPA}_{0.5}=14.82 \mathrm{~cm} / \mathrm{min}, p<0.001$; $\mathrm{PTZ}_{7.5}=21.90 \mathrm{~cm} / \mathrm{min}$ vs. $\mathrm{PTZ}_{7.5}+\mathrm{VPA}_{1}=10.95 \mathrm{~cm} / \mathrm{min}$, $p<0.001 ; \mathrm{PTZ}_{7.5}=19.95 \mathrm{~cm} / \mathrm{min}$ vs. $\mathrm{PTZ}_{7.5}+$ $\mathrm{VPA}_{2}=6.96 \mathrm{~cm} / \mathrm{min}, p<0.001 ; \mathrm{PTZ}_{7.5}=17.21 \mathrm{~cm} / \mathrm{min}$ vs. $\mathrm{PTZ}_{7.5}+\mathrm{VPA}_{3}=6.19 \mathrm{~cm} / \mathrm{min}, p<0.001$ ). Freezing observed in post-transitions in dark periods was corrected in cotreatments with $\mathrm{VPA}_{2}$ (Fig. 2c, Table 2, $\mathrm{PTZ}_{7.5}=5.61$ vs. $\left.\mathrm{PTZ}_{7.5}+\mathrm{VPA}_{2}=7.55 \mathrm{~cm} / \mathrm{min}, p<0.001\right)$, and this was true in all successive time periods (Fig. 2b and Supplementary Table 3).

We analyzed the third parameter, light-dependent center avoidance in post-transitions for $\mathrm{VPA}_{2}$ concentration. In light periods, the lack of center avoidance by $\mathrm{PTZ}_{7.5}$-alone-treated larvae was reversed in $\mathrm{PTZ}_{7.5}+\mathrm{VPA}_{2}$-co-treated larvae in both swim speeds: S2 (Fig. $2 \mathrm{f} \mathrm{PTZ}_{7.5}=1.12 \mathrm{~cm} / \mathrm{min}$ vs. $\mathrm{PTZ}_{7.5}+\mathrm{VPA}_{2}=0.39 \mathrm{~cm} / \mathrm{min}, p<0.001$ ); and $\mathrm{S} 3$ (Fig. $2 \mathrm{~g}$, $\mathrm{PTZ}_{7.5}=1.44 \mathrm{~cm} / \mathrm{min}$ vs. $\mathrm{PTZ}_{7.5}+\mathrm{VPA}_{2}=0.31 \mathrm{~cm} / \mathrm{min}$, $p<0.001$ ). In dark periods, center avoidance seen only in PTZ $_{7.5}$-alone-treated larvae was also significantly reversed in co-treated larvae in swim speed, S2 (Fig. 2f, $\mathrm{PTZ}_{7.5}=0.48 \mathrm{~cm} /$ min vs. $\mathrm{PTZ}_{7.5}+\mathrm{VPA}_{2}=1.27 \mathrm{~cm} / \mathrm{min}, p<0.001$ ). Thus, PTZaltered light-dependent center avoidance was significantly reversed in at least one swim speed in all successive post-

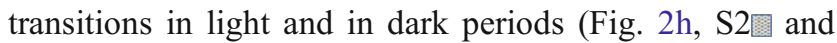

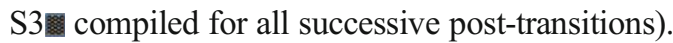

\section{Valeriana officinalis reverses $\mathrm{PTZ}_{7.5}$-altered light-dependent swimming behavior}

Next, we wanted to see how a complex mixture like a plant crude extract of unknown composition could reverse $\mathrm{PTZ}_{7.5^{-}}$ altered swimming. To establish a dose-response profile, we treated larvae with four concentrations of aqueous valerian root extracts $\left(\right.$ Val $1 \mathrm{mg} / \mathrm{ml}=\mathrm{Val}_{1}$, Val $2.5 \mathrm{mg} / \mathrm{ml}=\mathrm{Val}_{2.5}$, Val $5 \mathrm{mg} / \mathrm{ml}=\mathrm{Val}_{5}$, and $\mathrm{Val} 7 \mathrm{mg} / \mathrm{ml}=\mathrm{Val}_{7}$ ). We noticed a number of features not observed previously with the VPA treatments. In light conditions, across all Val concentrations, Val-alonetreated animals (Fig. 3a top panels, $-0-$ ) were always traveling more than untreated larvae $(-0-)$ suggesting moderate hyperactivity (Supplementary Table 6: Unt $=2.88 \mathrm{~cm} / \mathrm{min}$ vs. $\mathrm{Val}_{1}=4.59 \mathrm{~cm} / \mathrm{min}, p=0.05 ; \mathrm{Unt}=2.62 \mathrm{~cm} / \mathrm{min} \mathrm{vs}$. $\mathrm{Val}_{2.5}=4.29 \mathrm{~cm} / \mathrm{min}, p=0.044 ; \mathrm{Unt}=3.60 \mathrm{~cm} / \mathrm{min} \mathrm{vs}$. $\mathrm{Val}_{5}=10.00 \mathrm{~cm} / \mathrm{min}, p<0.001 ; \mathrm{Unt}=2.61 \mathrm{~cm} / \mathrm{min} \mathrm{vs}$. $\mathrm{Val}_{7}=6.33 \mathrm{~cm} / \mathrm{min}, p<0.001$ ). Interestingly in dark conditions, this hyperactivity was decreasing in a concentrationdependent manner $\left(\mathrm{Unt}=10.24 \mathrm{~cm} / \mathrm{min}\right.$ vs. $\mathrm{Val}_{1}=15.09 \mathrm{~cm} /$ $\min , p<0.001$; Unt $=9.88 \mathrm{~cm} / \mathrm{min}$ vs. $V_{2 a} .5=13.31 \mathrm{~cm} / \mathrm{min}$, $p<0.001 ; \mathrm{Unt}=10.86 \mathrm{~cm} / \mathrm{min}$ vs. $\mathrm{Val}_{5}=10.58 \mathrm{~cm} / \mathrm{min}$, $p=0.788 ; \mathrm{Unt}=10.67 \mathrm{~cm} / \mathrm{min}$ vs. $\mathrm{Val}_{7}=8.38 \mathrm{~cm} / \mathrm{min}$, $p<0.001$ ). Noticeably, animals treated with $\mathrm{Val}_{5}$ and $\mathrm{Val}_{7}$ seemed to only mildly adjust distances in response to light and dark changes. Furthermore, in light periods, the swimming activity of Val-alone-treated larvae vs. activity of cotreated $\mathrm{PTZ}_{7.5}+$ Val larvae was only significantly different in the two lower Val concentrations $\left(\mathrm{Val}_{1}=4.59 \mathrm{~cm} / \mathrm{min}\right.$ vs. $\mathrm{PTZ}_{7.5}+\mathrm{Val}_{1}=15.09 \mathrm{~cm} / \mathrm{min}, p<0.001 ; \mathrm{Val}_{2.5}=4.29 \mathrm{~cm} /$ min vs. $\left.\mathrm{PTZ}_{7.5}+\mathrm{Val}_{2.5}=9.00 \mathrm{~cm} / \mathrm{min}, p<0.001\right)$. The same was true in dark periods $\left(\mathrm{Val}_{1}=15.09 \mathrm{~cm} / \mathrm{min}\right.$ vs. $\mathrm{PTZ}_{7.5}+$ $\mathrm{Val}_{1}=9.04 \mathrm{~cm} / \mathrm{min}, p<0.001 ; \mathrm{Val}_{2.5}=13.31 \mathrm{~cm} / \mathrm{min}$ vs. $\left.\mathrm{PTZ}_{7.5}+\mathrm{Val}_{2.5}=7.66 \mathrm{~cm} / \mathrm{min}, p<0.001\right)$. Remarkably, for the two higher concentrations, distances traveled by Val alone and PTZ + Val-co-treated larvae were similar.

Next, we compared overall distances traveled by $\mathrm{PTZ}_{7.5^{-}}$ alone-treated larvae (Fig. 3a bottom panels, $-\mathbf{-}$ ) with overall distances traveled by $\mathrm{PTZ}_{7.5}+$ Val-co-treated larvae ( - ). In light periods, we observed a Val concentration-dependent reduction of the $\mathrm{PTZ}_{7.5}$-induced hyperactivity starting with $\mathrm{Val}_{2.5}$ co-treatments $\left(\mathrm{PTZ}_{7.5}=14.55 \mathrm{~cm} / \mathrm{min}\right.$ vs. $\mathrm{PTZ}_{7.5}+$ $\mathrm{Val}_{2.5}=9.00 \mathrm{~cm} / \mathrm{min}, p<0.001 ; \mathrm{PTZ}_{7.5}=15.77 \mathrm{~cm} / \mathrm{min}$ vs. $\mathrm{PTZ}_{7.5}+\mathrm{Val}_{5}=9.25 \mathrm{~cm} / \mathrm{min}, p<0.001 ; \mathrm{PTZ}_{7.5}=10.30 \mathrm{~cm} /$ min vs. PTZ $\left.7.5+\mathrm{Val}_{7}=5.98 \mathrm{~cm} / \mathrm{min}, p<0.001\right)$. Remarkably in dark periods, averaged overall distances were not significantly different. However, when observing the behavior minute by minute, it was clearly different also starting with $\mathrm{Val}_{2.5}$ co-treatments (compare - 4 and larvae

lines in Fig. 3a bottom panels, gray boxes). $\mathrm{PTZ}_{7.5}$-treated animals were gradually increasing distances from $\sim 2 \mathrm{~cm} / \mathrm{min}$ to $\sim 15 \mathrm{~cm} / \mathrm{min}$ while co-treated animals were steadily traveling $\sim 8 \mathrm{~cm} / \mathrm{min}$. 
In post-transitions, the strong hyperactivity observed in light periods in $\mathrm{PTZ}_{7.5}$-treated larvae was corrected in a concentration-dependent manner also emerging at $\mathrm{Val}_{2.5}$ (Fig. 3a, with $\mathrm{Val}_{5}$ also shown in $\mathrm{b}$ and c. $\mathrm{PTZ}_{7.5}=20.29 \mathrm{~cm} /$ min vs. $\mathrm{PTZ}_{7.5}+\mathrm{Val}_{2.5}=12.85 \mathrm{~cm} / \mathrm{min}, p<0.001$; $\mathrm{PTZ}_{7.5}=21.13 \mathrm{~cm} / \mathrm{min}$ vs. $\mathrm{PTZ}_{7.5}+\mathrm{Val}_{5}=8.42 \mathrm{~cm} / \mathrm{min}$, $p<0.001 ; \mathrm{PTZ}_{7.5}=14.10 \mathrm{~cm} / \mathrm{min}$ vs. $\mathrm{PTZ}_{7.5}+\mathrm{Val}_{7}=6.85 \mathrm{~cm} /$ min, $p<0.001)$. Similarly in dark periods, freezing was corrected in a concentration-dependent manner in cotreatments starting with $\mathrm{Val}_{2.5}\left(\mathrm{PTZ}_{7.5}=5.16 \mathrm{~cm} / \mathrm{min}\right.$ vs. $\mathrm{PTZ}_{7.5}+\mathrm{Val}_{2.5}=11.34 \mathrm{~cm} / \mathrm{min}, p<0.001 ; \mathrm{PTZ}_{7.5}=6.48 \mathrm{~cm} /$ min vs. PTZ $7.5+\mathrm{Val}_{5}=10.66 \mathrm{~cm} / \mathrm{min}, p<0.001$; $\mathrm{PTZ}_{7.5}=7.18 \mathrm{~cm} / \mathrm{min}$ vs. $\mathrm{PTZ}_{7.5}+\mathrm{Val}_{7}=9.09 \mathrm{~cm} / \mathrm{min}$, $p=0.021)$. In $\mathrm{PTZ}_{7.5}+\mathrm{Val}_{5}$ co-treatments in all successive post-transitions PTZ-altered swimming, hyperactivity in light and freezing in dark were both significantly reversed (Fig. 3c and Supplementary Table 7), except for freezing in the last dark period (Fig. 3b, gray box D4), thus clearly highlighting a strong corrective effect in co-treatments with $\mathrm{Val}_{5}$. We analyzed further the light-dependent center avoidance at this concentration.

In light periods, lack of center avoidance which we observed in $\mathrm{PTZ}_{7.5}$-alone-treated larvae was reversed in $\mathrm{PTZ}_{7.5}+\mathrm{Val}_{5}$-co-treated larvae in both swim speeds: S2 (Fig. 3f, $\mathrm{PTZ}_{7.5}=3.62 \mathrm{~cm} / \mathrm{min}$ and $\mathrm{PTZ}_{7.5}+\mathrm{Val}_{5}=1.51 \mathrm{~cm} /$ min, $p<0.001$ ) and S3 (Fig. 3g, $\mathrm{PTZ}_{7.5}=1.96 \mathrm{~cm} / \mathrm{min}$ vs. $\left.\mathrm{PTZ}_{7.5}+\mathrm{Val}_{5}=0.57 \mathrm{~cm} / \mathrm{min}, p<0.001\right)$. In dark periods, the heightened center avoidance seen in $\mathrm{PTZ}_{7.5}$-alone-treated larvae was reversed in $\mathrm{PTZ}_{7.5}+\mathrm{Val}_{5}$-co-treated larvae in $\mathrm{S} 2$ swim speed (Fig. 2f, $\mathrm{PTZ}_{7.5}=1.36$ vs. PTZ $7.5+$ $\mathrm{Val}_{5}=2.60 \mathrm{~cm} / \mathrm{min}, p=0.003$ ). Thus, PTZ-altered light-dependent center avoidance was significantly reversed in at least one swim speed in all successive post-transitions in light and

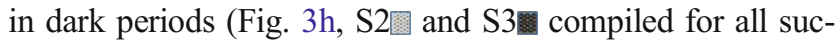
cessive post-transitions).

\section{$\mathrm{Val}_{5}$ reverses $\mathrm{PTZ}_{7.5}$ upregulated transcription of $c$-fos, npas $4 a$, and $b d n f$ in larval brain}

To confirm that the reversal of PTZ-altered swimming that we observed in Val treatments was caused by actual changes in brain activity, we checked how the transcriptional regulation of neuronal activity-regulated genes was affected by the different treatments. We assessed transcriptional changes in brains of untreated, $\mathrm{PTZ}_{7.5}$-alone-treated, Val ${ }_{5}$-alone-treated, and $\mathrm{PTZ}_{7.5}+\mathrm{Val}_{5}$-co-treated larvae by WISH (Fig. 4b). We further quantified the changes by qPCRs in whole larvae (Fig. 4c). In particular, we compared gene expression of a small group of selected genes: c-fos, npas $4 a$, gabral, gabgr2, ppya, and $b d n f$. These genes had all been previously described as transcriptionally upregulated in PTZ-treated zebrafish larvae (Baxendale et al. 2012).
To analyze the WISH and identify brain regions for each gene expression pattern, we compiled a schematic representation of a larval brain at $6 \mathrm{dpf}$ modified from Wullimann and Knipp (2000), Wullimann and Puelles (1999), and Wullimann et al. $(1999,1996)$ which we used as a frame of reference (Fig. 4a, lateral view on the left and dorsal projection on the right). We did not see significant changes for gabral, gabgr2, and ppya (data not shown), but we did for the three other genes: $c$-fos (Fig. 4b, top panels), npas4a (middle panels), and $b d n f$ (bottom panels). We found only basal weak expression for all three genes in untreated (first column) and in $\mathrm{Val}_{5^{-}}$ alone-treated (second column) larvae. As expected, we found a strongly upregulated expression for all three genes in brains of PTZ 7.5 -treated larvae (third column). The c-fos gene was strongly expressed in the dorsal and ventral telencephalon (palium and subpalium, respectively), in the diencephalon (preoptic region, posterior tuberculum, and hypothalamus), and in some discrete regions of the hindbrain. The npas $4 a$ gene was strongly expressed in the ventral telencephalon (subpalium) and ventral diencephalon (posterior tuberculum and hypothalamus), weakly expressed throughout the hindbrain with stronger staining of a subgroup of neurons in the middle/ventral portion of the medulla oblongata. The $c$-fos and npas $4 a$ expression patterns were only partially overlapping. However, the $b d n f$ expression domain seemed mostly comparable to the npas $4 a$ domain. Strikingly, in $\mathrm{PTZ}_{7.5}+$ $\mathrm{Val}_{5}$-co-treated animals (fourth column), we saw a drastic reduction in the expression domains of all three genes when compared to the ones found in $\mathrm{PTZ}_{7.5}$-alone-treated animals. We found only residual $c$-fos and npas $4 a$ staining in the ventral telencephalon of a few larvae. Thus, the PTZ-upregulated expression of all three genes was strongly reversed by cotreatments with $\mathrm{Val}_{5}$.

To confirm and quantify the transcriptional downregulation of those three genes, we performed qPCRs (Fig. 4c). We used the basal expression which we measured in untreated animals for each gene to set their expression level at 1 . We found that the expression level of $c$-fos (Fig. 4c, left panel) was increased by $\sim 5$-fold inVal ${ }_{5}$-alone-treated animals This was corroborating the milder hyperactivity seen in the behavioral assay with those treatments. In $\mathrm{PTZ}_{7.5}$-alone-treated animals, we found a $\sim 15$-fold increase in gene expression in line with the strong PTZ-altered swimming behavior. Remarkably, in $\mathrm{PTZ}_{7.5}+\mathrm{Val}_{5}$-co-treated larvae, we found only a $\sim 5$-fold increase in $c$-fos gene expression, similar to what we had found in $\mathrm{Val}_{5}$-alone treatments. Next, we analyzed the expression of npas $4 a$ (middle panel). We found a strong upregulation which was close to $\sim 20$-fold in $\mathrm{PTZ}_{7.5}$-alone-treated animals. In $\mathrm{PTZ}_{7.5}+\mathrm{Val}_{5}$-co-treated and in $\mathrm{Val}_{5}$-alonetreated larvae, we measured only basal expression similar to what we had found in untreated larvae. For $b d n f$ (right panel), we measured a 3-fold PTZ-induced upregulation, which was not found in co-treatments or $\mathrm{Val}_{5}$-alone treatments. Thus, the 
PTZ-induced upregulation of those two genes was completely abolished in co-treatments, fully corroborating the reversal of PTZ-altered swimming behavior.

\section{Discussion}

In this work, we demonstrate the robustness and sensitivity of a coupled behavioral-molecular approach in zebrafish larvae that we propose as a paradigm to screen at high throughput level complex mixtures of unknown composition for psychoactive efficacy in vivo. As a proxy for measuring psychoactivity, we assessed the reversal of a chemically altered swimming behavior in fish. Similar tests have been proposed to screen for neuro-therapeutics (Ellis and Soanes 2012). First, we showed that when applying PTZ, a commonly used anxiogenic/convulsive compound, at a set concentration ( PTZ $_{7.5}=7.5 \mathrm{mM}$ ), we could reproducibly alter a strong lightdependent swimming behavior in zebrafish larvae. We focused on three specific parameters during post-transitions of the light conditions which were characteristic of $\mathrm{PTZ}_{7.5}$-altered swimming: (1) hyperactivity in the light, (2) freezing in the dark, and (3) altered light-dependent center avoidance. Next, we assessed the reversal of those three parameters by co-treatment with known psychoactive molecule(s). Cotreatments with VPA, a synthetic derivate of valeric acid which is extracted from Val (Patočka 2010), reversed all three parameters in a concentration-dependent manner. More remarkably, co-treatments with crude root extracts of Valerian also reversed all three parameters in a concentrationdependent manner. Thus, we demonstrated the efficacy of the behavioral assay in detecting psychoactive effects in a crude extract prepared from Valerian powdered roots.

The underlying mode of action of reversal of the PTZaltered swimming remains to be determined. One obvious mode of action could be through the GABAergic system. It is thought that PTZ effects are mainly mediated through inhibition of $\mathrm{GABA}_{\mathrm{A}}$ receptors (Squires et al. 1984). VPA is known to potentiate GABAergic functions by increasing turnover of gamma-aminobutyric acid (GABA) (for review (Loscher 2002; Loscher and Vetter 1984)). Several lines of evidence show that Valerian extracts bind to the $\mathrm{GABA}_{\mathrm{A}}$ receptors and might act as an agonist (Cavadas et al. 1995). More recently, it was demonstrated that VPA also has histone deacetylase (HDAC) inhibitory properties (Phiel et al. 2001) linking its neuro-protective effects to modulation of gene expression (Nalivaeva et al. 2009). Future work should explore this possible mode of action for Valerian extracts.

We also found some effects that were treatment-specific. With the higher concentration of VPA $(3 \mathrm{mM}), \mathrm{VPA}_{3}$-alonetreated larvae were swimming less at all time points measured. In addition, freezing in post-transitions in dark was not significantly reversed in $\mathrm{PTZ}_{7.5}+\mathrm{VPA}_{3}$-co-treated animals unlike what we had seen with the lower VPA 2 concentration Both of those effects could be due to sedation, which is a side effect of this drug at high dosage that has been extensively observed in other animal models and in humans (Chateauvieux et al. 2010; Chiu et al. 2013; Nalivaeva et al. 2009). This highlights the sensitivity of our assay and also validates the relevance for human health of potential finding/testing performed in this lower vertebrate.

Noticeably, we did not observe those apparent sedative effects in Val treatments. In fact, we found at all concentrations tested in Val-alone treatments a generalized significant increase in swimming activity at all measured time points, for the exception of treatments with the higher concentration $\mathrm{Val}_{7}$ during dark periods. Interestingly, various reliable user reports mention hyperactivity and concentration-dependent variability in effects of Valerian extracts (https://naturalmedicines. therapeuticresearch.com/databases/).

Maybe more surprising was the observation that with the two higher doses of Val, PTZ $7.5+$ Val-co-treated animals behaved in a strikingly similar manner to Val-alone-treated larvae. In other words, co-treated animals were behaving as if PTZ was absent. This was particularly remarkable knowing the strong effects seen in PTZ-alone treatments. This was never observed with VPA. Arguably, we were observing synergic action of the multiple active compounds present in Val extracts. One possible explanation could be that active compounds compete "in vivo" with PTZ for binding to GABA A $_{\text {. }}$ An alternative explanation could be that active compounds induce conformational modification of the receptors resulting in the inability for PTZ to bind. A strong candidate for exerting one or both of those two effects is valerenic acid (VA) which is a GABA analog and has been implicated as the main active substance in Val extracts in various studies (Becker et al. 2014) (Benke et al. 2009) (Trauner et al. 2008). We tried to assess VA effects with our assay, but even at low dosages VA was highly toxic to larvae. This actually highlights one of the shortcomings of such in vivo assays. As larvae are exposed through their entire body, toxicity because of high dosage and/or off-target effects can be high and secondary effects can mask other results.

In addition to resolving the mechanism underpinning Val potent psychoactive effects, major challenges remain. To cite a few, how representative were the tested samples of Val? Val composition can vary with harvest, season, growth condition, and origin (Patočka 2010). However, that could easily be adjusted by testing different preparations. How does an effective dosage in zebrafish larvae translate to an adequate posology in humans? This is a real challenge as the mode of administration can drastically change the composition of the final product through digestion or filtering through the blood-brain barrier (BBB). In zebrafish, a BBB is present as early as $3 \mathrm{dpf}$ and at least partially functional (Eliceiri et al. 2011). Interestingly, Val extracts have been shown to contain high quantities of 
GABA, but it is generally admitted that those would not cross the BBB. This could be tested by labeling GABA molecules and observing their distribution after exposure in zebrafish larvae.

In parallel to behavioral measures, we measured transcriptional changes in a small number of known synaptic activityinduced genes, known to be regulated by PTZ treatments (Baxendale et al. 2012). Our molecular data strongly corroborated our behavioral data but also provided the first molecular evidence of the psychoactive potency of a plant crude extract. $C$-fos has become the gold standard for detecting synaptic activity (Zhang et al. 2002). We showed that $c$-fos upregulation was 3-fold lower in co-treatments than in PTZalone treatments, which correlated nicely with the reversal of PTZ-altered swimming activity. Furthermore, levels of gene expression of $c$-fos were similar in $\mathrm{Val}_{5}$-alone-treated and in $\mathrm{PTZ}_{7.5}+\mathrm{Val}_{5}$-co-treated animals, which again corroborated the striking similarity in behavior that we had observed in those two treatments. Npas $4 a$, a more recently discovered transcription factor, is involved in regulating excitatoryinhibitory balance within neural circuits (Bloodgood et al. 2013; Lin et al. 2008; Spiegel et al. 2014). Its importance in neurological disorders including bipolar disorders was clearly established but not fully elucidated (Coutellier et al. 2012; Jaehne et al. 2015). One putative downstream target of $c$-fos and npas $4 a$ is the neurotrophic factor $b d n f$ (Greenberg et al. 2009; Lin et al. 2008). Neuronal activity-dependent upregulation of bdnf is well known (Zhang et al. 2002), and both $\mathrm{GABA}_{\mathrm{A}}$ receptors can be modulated by bdnf (Marty et al. 2000). We found that both npas $4 a$ and bdnf were transcriptionally regulated by Val treatments. Three other genes (ppya, gabra1, and gbrg2) which are widely expressed in zebrafish larval brain as early as $2 \mathrm{dpf}$ (Baxendale et al. 2012) did not show a significant regulation with either methods, WISH or qPCRs, maybe because time of exposure to PTZ was too short. Both $c$-fos and npas $4 a$ are immediate early response (IER) genes which are activated within minutes and without needing protein neo-synthesis (Flavell and Greenberg 2008). By comparison, $b d n f$ will only be induced after at least $1 \mathrm{~h}$ of exposure (Flavell and Greenberg 2008) (Marty et al. 2000). Consistent with this, we found that $b d n f$ was the least activated gene of the three.

It will be of importance to effectively decorticate gene cascades involved in the corrective action of any psychoactive drug isolated with a screen such as the one we describe here. However, for now, a major limiting factor is the fact that larval zebrafish brain is still very poorly documented. Precise localization of gene expression domains is indispensable to understand which neural circuitries are involved. This problem should be resolving as a growing number of laboratories are working with this animal model.

Nevertheless, our findings suggest high conservation in neural circuitries governing anxiety and mood-stabilizing mechanisms from fish to humans. This validated our low-cost, potent screening platform for neuroactive compounds which could be detected even in a crude plant preparation. This screening tool will advance discovery of new psychoactive molecules because it worked with minimal preparation/ standardization of plant extracts and easy drug application. Ultimately, this work can be extended to test any ethnobotanical plant of interest. Once crude extracts show psychoactivity, successive purification steps or micro-fractionation to isolate bioactive component(s) can be done (Challal et al. 2014); (Bohni et al. 2013). In vivo competition-binding assays with agonist/antagonist of specific receptors could be another continuation. In addition to dissect drug targets, this assay can be performed in mutant larvae which are defective for a given brain receptor for example. The combination of behavioralmolecular assays with the genetic power of this model will undoubtedly advance drug discovery.

Acknowledgments This work was supported by Research Centers for Minority Institutions of National Institutions of Health (RCMI/NIH, Seed Monies; award no. G12 RR03051). Graduate students BA. T-H and C. RF were funded by the Minority Biomedical Research Support ProgramResearch Initiative for Scientific Enhancement (MBRS-RISE award no. 2 R25 GM061838) at the Medical Science Campus University of Puerto Rico (MSC-UPR); graduate student LR. C was funded by the National Science Foundation-Center of Research Excellence in Science and Technology (NSF-CREST: Puerto Rican Center of Environmental Neuroscience (PRCEN), award no. HRD-1137725). L.G-S, N.P-R, and E. S-P were supported by the National Institute on Minority Health and Health Disparities of the National Institutes of Health (NIMHHD/NIH, award no. 2U54MD007587). Infrastructure and instrumentation were available through a Pathway to Independence grant from the National Institutions of Health (NIH-K99/R00-NIH, award no. R00-DC009443) and a grant from the Puerto-Rican Science Trust to M. B. We want to thank Dr. Vincent Cunliffe for the generous gift of plasmids for in situ antisense probes, Dr. Guillermo Yudowski and Dr. Greg Quirk for critical reading of the manuscript, and all the undergraduates (Andre Calimano, Wendy Aquino, Roberto Rodriguez Morales, and Normarie Herrera) for help with fish husbandry.

\section{Compliance with ethical standards}

Conflict of interest All authors declared having no conflict of interest.

Open Access This article is distributed under the terms of the Creative Commons Attribution 4.0 International License (http:// creativecommons.org/licenses/by/4.0/), which permits unrestricted use, distribution, and reproduction in any medium, provided you give appropriate credit to the original author(s) and the source, provide a link to the Creative Commons license, and indicate if changes were made.

\section{References}

Baxendale S et al (2012) Identification of compounds with anticonvulsant properties in a zebrafish model of epileptic seizures. Disease Models Mechanisms 5:773-784. doi:10.1242/dmm.010090 
Becker A, Felgentreff F, Schroder H, Meier B, Brattstrom A (2014) The anxiolytic effects of a Valerian extract is based on valerenic acid. BMC Complementary Alternative Med 14:267. doi:10.1186/14726882-14-267

Benke D et al (2009) GABA A receptors as in vivo substrate for the anxiolytic action of valerenic acid, a major constituent of valerian root extracts. Neuropharmacology 56:174-181. doi:10.1016/j. neuropharm.2008.06.013

Bent S, Padula A, Moore D, Patterson M, Mehling W (2006) Valerian for sleep: a systematic review and meta-analysis. Am J Med 119:10051012. doi:10.1016/j.amjmed.2006.02.026

Berghmans S, Hunt J, Roach A, Goldsmith P (2007) Zebrafish offer the potential for a primary screen to identify a wide variety of potential anticonvulsants. Epilepsy Res 75:18-28. doi:10.1016/j.eplepsyres. 2007.03.015

Bloodgood BL, Sharma N, Browne HA, Trepman AZ, Greenberg ME (2013) The activity-dependent transcription factor NPAS4 regulates domainspecific inhibition. Nature 503:121-125. doi:10.1038/nature12743

Bohni $\mathrm{N}$ et al (2013) Integration of microfractionation, qNMR and zebrafish screening for the in vivo bioassay-guided isolation and quantitative bioactivity analysis of natural products. PLoS One 8, e64006. doi:10.1371/journal.pone.0064006

Cavadas C, Araujo I, Cotrim MD, Amaral T, Cunha AP, Macedo T, Ribeiro CF (1995) In vitro study on the interaction of Valeriana officinalis L. extracts and their amino acids on GABAA receptor in rat brain. Arzneimittelforschung 45:753-755

Challal S et al (2014) Zebrafish bioassay-guided microfractionation identifies anticonvulsant steroid glycosides from the Philippine medicinal plant Solanum torvum. ACS Chem Neurosci 5:993-1004. doi: $10.1021 / \mathrm{cn} 5001342$

Chateauvieux S, Morceau F, Dicato M, Diederich M (2010) Molecular and therapeutic potential and toxicity of valproic acid. J Biomed Biotechnol. doi:10.1155/2010/479364

Chiu CT, Wang Z, Hunsberger JG, Chuang DM (2013) Therapeutic potential of mood stabilizers lithium and valproic acid: beyond bipolar disorder. Pharmacol Rev 65:105-142. doi:10.1124/pr.111.005512

Coutellier L, Beraki S, Ardestani PM, Saw NL, Shamloo M (2012) Npas4: a neuronal transcription factor with a key role in social and cognitive functions relevant to developmental disorders. PLoS One 7, e46604. doi:10.1371/journal.pone.0046604

Del Valle-Mojica LM, Ayala-Marin YM, Ortiz-Sanchez CM, TorresHernandez BA, Abdalla-Mukhaimer S, Ortiz JG (2011a) Selective interactions of valeriana officinalis extracts and valerenic acid with $[\mathrm{H}]$ glutamate binding to rat synaptic membranes. Evid Based Complement Alternat Med 2011:403591

Del Valle-Mojica LM, Cordero-Hernandez JM, Gonzalez-Medina G, Ramos-Velez I, Berrios-Cartagena N, Torres-Hernandez BA, Ortiz JG (2011b) Aqueous and Ethanolic Valeriana officinalis Extracts Change the Binding of Ligands to Glutamate Receptors Evidencebased complementary and alternative medicine: eCAM 2011: 891819 doi:10.1155/2011/891819

Dietz BM, Mahady GB, Pauli GF, Farnsworth NR (2005) Valerian extract and valerenic acid are partial agonists of the 5-HT5 a receptor in vitro Brain research. Mol Brain Res 138:191-197. doi:10.1016/j. molbrainres.2005.04.009

Eliceiri BP, Gonzalez AM, Baird A (2011) Zebrafish model of the bloodbrain barrier: morphological and permeability studies. Methods Mol Biol 686:371-378. doi:10.1007/978-1-60761-938-3 18

Ellis LD, Soanes KH (2012) A larval zebrafish model of bipolar disorder as a screening platform for neuro-therapeutics. Behav Brain Res 233:450-457. doi:10.1016/j.bbr.2012.05.043

Ellis LD, Seibert J, Soanes KH (2012) Distinct models of induced hyperactivity in zebrafish larvae. Brain Res 1449:46-59. doi:10.1016/j. brainres.2012.02.022

Fernandez-San-Martin MI, Masa-Font R, Palacios-Soler L, SanchoGomez P, Calbo-Caldentey C, Flores-Mateo G (2010)
Effectiveness of Valerian on insomnia: a meta-analysis of randomized placebo-controlled trials. Sleep Med 11:505-511. doi:10.1016/ j.sleep.2009.12.009

Flavell SW, Greenberg ME (2008) Signaling mechanisms linking neuronal activity to gene expression and plasticity of the nervous system. Annu Rev Neurosci 31:563-590. doi:10.1146/annurev.neuro.31. 060407.125631

Fugh-Berman A, Cott JM (1999) Dietary supplements and natural products as psychotherapeutic agents. Psychosom Med 61:712-728

Greenberg ME, Xu B, Lu B, Hempstead BL (2009) New insights in the biology of BDNF synthesis and release: implications in CNS function. J Neuroscience: Off J Soc Neuroscience 29:12764-12767. doi: 10.1523/JNEUROSCI.3566-09.2009

Haffter $P$ et al (1996) The identification of genes with unique and essential functions in the development of the zebrafish. Danio Rerio Dev 123:1-36

Hattesohl M, Feistel B, Sievers H, Lehnfeld R, Hegger M, Winterhoff H (2008) Extracts of Valeriana officinalis L. s.l. show anxiolytic and antidepressant effects but neither sedative nor myorelaxant properties. Phytomedicine: Int J Phytotherapy Phytopharmacology 15:215. doi:10.1016/j.phymed.2007.11.027

Jaehne EJ, Klaric TS, Koblar SA, Baune BT, Lewis MD (2015) Effects of Npas4 deficiency on anxiety, depression-like, cognition and sociability behaviour. Behav Brain Res 281:276-282. doi:10.1016/j.bbr. 2014.12.044

Kimmel CB, Ballard WW, Kimmel SR, Ullmann B, Schilling TF (1995) Stages of embryonic development of the zebrafish. Dev Dynamics: Off Publ Am Assoc Anatomists 203:253-310. doi:10.1002/aja. 1002030302

Kristofco LA, Cruz LC, Haddad SP, Behra ML, Chambliss CK, Brooks BW (2015) Age matters: developmental stage of Danio rerio larvae influences photomotor response thresholds to diazinion or diphenhydramine. Aquat Toxicol. doi:10.1016/j.aquatox.2015.09.011

Lacher SK, Mayer R, Sichardt K, Nieber K, Muller CE (2007) Interaction of valerian extracts of different polarity with adenosine receptors: identification of isovaltrate as an inverse agonist at A1 receptors. Biochem Pharmacol 73:248-258. doi:10.1016/j.bcp.2006.09.029

LaFave MC, Varshney GK, Vemulapalli M, Mullikin JC, Burgess SM (2014) A defined zebrafish line for high-throughput genetics and genomics: NHGRI-1. Genetics 198:167-170. doi:10.1534/ genetics.114.166769

Leyland A. GH (2004) Multilvel Modelling of health Statistics.

Lin Y et al (2008) Activity-dependent regulation of inhibitory synapse development by Npas4. Nature 455:1198-1204. doi:10.1038/nature07319

Livak KJ, Schmittgen TD (2001) Analysis of relative gene expression data using real-time quantitative PCR and the 2(-Delta Delta C(T)) Method. Methods 25:402-408. doi:10.1006/meth.2001.1262

Loscher W (2002) Basic pharmacology of valproate: a review after 35 years of clinical use for the treatment of epilepsy. CNS Drugs 16:669-694

Loscher W, Vetter M (1984) Drug-induced changes in GABA content of nerve endings in 11 rat brain regions. Correlation Pharmacological Effects Neuroscience Letters 47:325-331

MacPhail RC, Brooks J, Hunter DL, Padnos B, Irons TD, Padilla S (2009) Locomotion in larval zebrafish: influence of time of day, lighting and ethanol. Neurotoxicology 30:52-58. doi:10.1016/j. neuro.2008.09.011

MacRae CA, Peterson RT (2015) Zebrafish as tools for drug discovery. Nat Rev Drug Discov 14:721-731. doi:10.1038/nrd4627

Marty S, Wehrle R, Sotelo C (2000) Neuronal activity and brain-derived neurotrophic factor regulate the density of inhibitory synapses in organotypic slice cultures of postnatal hippocampus. J Neurosci Off J Soc Neurosci 20:8087-8095

Murphy K, Kubin ZJ, Shepherd JN, Ettinger RH (2010) Valeriana officinalis root extracts have potent anxiolytic effects in laboratory rats. Phytomedicine: Int J Phytotherapy Phytopharmacology 17: 674-678. doi:10.1016/j.phymed.2009.10.020 
Muto A, Kawakami K (2013) Prey capture in zebrafish larvae serves as a model to study cognitive functions. Frontiers Neural Circuits 7:110. doi:10.3389/fncir.2013.00110

Nalivaeva NN, Belyaev ND, Turner AJ (2009) Sodium valproate: an old drug with new roles. Trends Pharmacol Sci 30:509-514. doi:10. 1016/j.tips.2009.07.002

Parker MO et al (2014) The utility of zebrafish to study the mechanisms by which ethanol affects social behavior and anxiety during early brain development. Prog Neuro-Psychopharmacol Biol Psychiatry 55:94-100. doi:10.1016/j.pnpbp.2014.03.011

Patočka JJ (2010) Biomedically relevant chemical constituents of Valeriana officinalis. J Appl Biomed 8:11-18

Phiel CJ, Zhang F, Huang EY, Guenther MG, Lazar MA, Klein PS (2001) Histone deacetylase is a direct target of valproic acid, a potent anticonvulsant, mood stabilizer, and teratogen. J Biol Chem 276:36734 36741. doi:10.1074/jbc.M101287200

Raetsch C (2005) The encyclopedia pf psychoactive plants. In: Press PS (ed) Ethnophamacology and its applications. p 942

Rennekamp AJ, Peterson RT (2015) 15 years of zebrafish chemical screening. Curr Opin Chem Biol 24:58-70. doi:10.1016/j.cbpa. 2014.10.025

Rezvani ME, Roohbakhsh A, Allahtavakoli M, Shamsizadeh A (2010) Anticonvulsant effect of aqueous extract of Valeriana officinalis in amygdala-kindled rats: possible involvement of adenosine. J Ethnopharmacol 127:313-318. doi:10.1016/j.jep.2009.11.002

Spiegel I et al (2014) Npas4 regulates excitatory-inhibitory balance within neural circuits through cell-type-specific gene programs. Cell 157:1216-1229. doi:10.1016/j.cell.2014.03.058

Squires RF, Saederup E, Crawley JN, Skolnick P, Paul SM (1984) Convulsant potencies of tetrazoles are highly correlated with actions on GABA/benzodiazepine/picrotoxin receptor complexes in brain. Life Sci 35:1439-1444

Streisinger G, Walker C, Dower N, Knauber D, Singer F (1981) Production of clones of homozygous diploid zebra fish (Brachydanio rerio). Nature 291:293-296

Taibi DM, Vitiello MV, Barsness S, Elmer GW, Anderson GD, Landis CA (2009) A randomized clinical trial of valerian fails to improve self-reported, polysomnographic, and actigraphic sleep in older women with insomnia. Sleep Med 10:319-328. doi:10.1016/j. sleep.2008.02.001

Tamhane AC, Bechhofer RE (1979) A two-stage minimax procedure with screening for selecting the largest normal mean (II): an improved PCS lower bound and associated tables. Communications Statistics-Theory Methods 8:337-358

Thisse C, Thisse B (2008) High-resolution in situ hybridization to wholemount zebrafish embryos. Nat Protoc 3:59-69. doi:10.1038/nprot. 2007.514

Torres-Hernández BA, Del Valle-Mojica LM, Ortíz JG (2015) Valerenic acid and Valeriana officinalis extracts delay onset of Pentylenetetrazole (PTZ)-Induced seizures in adult Danio rerio (Zebrafish). BMC Complement Alternat Med 15:228. doi:10.1186/ s12906-015-0731-3

Trauner G, Khom S, Baburin I, Benedek B, Hering S, Kopp B (2008) Modulation of GABAA receptors by valerian extracts is related to the content of valerenic acid. Planta Med 74:19-24. doi:10.1055/s2007-993761

Westerfield M (1993) The Zebrafish book: a guide for the laboratory use of zebrafish (Brachydanio rerio) Eugene OR, University of Oregon Press

Wullimann MF, Knipp S (2000) Proliferation pattern changes in the zebrafish brain from embryonic through early postembryonic stages. Anat Embryol 202:385-400

Wullimann MF, Puelles L (1999) Postembryonic neural proliferation in the zebrafish forebrain and its relationship to prosomeric domains. Anat Embryol 199:329-348

Wullimann MF, Rupp, B., Reichert, H. (1996) Neuroanatomy of the zebrafish brain Birkhauser edition isnb 3-7643-5120-9

Wullimann MF, Puelles L, Wicht H (1999) Early postembryonic neural development in the zebrafish: a 3-D reconstruction of forebrain proliferation zones shows their relation to prosomeres. Eur J Morphol $37: 117-121$

Zhang J, Zhang D, McQuade JS, Behbehani M, Tsien JZ, Xu M (2002) cfos regulates neuronal excitability and survival. Nat Genet 30:416420. doi:10.1038/ng859 